\title{
VALORACIÓN PROBATORIA DE LOS DOCUMENTOS PÚBLICOS MERCANTILES: PREVALENCIA DE CRITERIOS JURÍDICOS
}

\author{
Evidentiary valuation of commercial \\ public documents: preference of legal \\ criteria
}

\author{
Claudio Meneses PACheco* \\ Universidad de Valparaíso
}

\begin{abstract}
RESUMEN
El propósito de este trabajo es ofrecer una explicación acerca de la valoración probatoria de los documentos públicos mercantiles en la que se considera la diversidad de criterios concurrentes, asignando una preferencia a parámetros jurídicos derivados de las finalidades que tiene la fe pública en el Derecho comercial. Se abandonan las categorías doctrinales denominadas "prueba legal" y "prueba libre", para proponer una perspectiva integrada de los factores que participan en la actividad jurisdiccional de valoración de evidencias y decisión sobre los hechos. Se postula la necesidad de mantener una comunión entre, por un lado, las medidas previstas por el Derecho comercial para alcanzar un desarrollo seguro y eficiente del tráfico y, por otro, el juzgamiento de los hechos en procesos donde se discuten cuestiones asociadas a actos, contratos y operaciones mercantiles.
\end{abstract}

\section{PALABRAS CLAVE}

Valoración de la prueba, documentos mercantiles y fe pública, prevalencia de criterios jurídicos.

\section{ABSTRACT}

The purpose of this paper is to offer a explanation regarding the evidentiary valuation of commercial public documents in which a diversity of concurring criteria are considered, assigning a preference to the legal criteria derived from the objectives of public trust in Commercial Law. We abandon the categories that the doctrine denominates "Legal Proof" and "Free Proof", and propose an integrated perspective of the elements that participate in the judicial activity of evidentiary valuation and decision on facts. We hold the need to maintain a communion between, on one hand, the measures established by Commercial Law to reach a safe and efficient development of trade and, on the other hand, the judgement of facts in processes where matters regarding commercial acts, contracts and operations are being discussed.

\section{KEYWORDS}

Evidentiary valuation, commercial documents and public trust, prevalence of legal criteria.

\section{Introducción ${ }^{* *}$}

La valoración de la prueba es una actividad de juzgamiento por medio de la cual los tribunales deben determinar si las evidencias aportadas a un proceso brindan suficiente confirmación a las alegaciones de hecho planteadas por las partes, para con base en ello

\footnotetext{
* Profesor de Derecho procesal, Universidad de Valparaíso. Doctor en Derecho, Universidad de los Andes, Santiago, Chile. Correos electrónicos: claudio.meneses@uv.cl / cmp@mackaycia.cl. Este trabajo forma parte del proyecto de investigación Fondecyt № 11171164, titulado "Fe pública y documentos mercantiles: estudio de la prueba documental pública en el Derecho comercial chileno", del cual el autor es investigador responsable. Se hace público el agradecimiento a los profesores Jorge Larroucau y Johann Benfeld por las observaciones efectuadas en el coloquio titulado "Valoración legal de la prueba y documentos públicos mercantiles" (Escuela de Derecho, Universidad de Valparaíso, septiembre 2019), que sirvieron de guía para reformular varios puntos de vista del presente trabajo.

${ }^{* *}$ Abreviaturas: $\mathrm{CC}=$ Código civil $/ \mathrm{CCom}=$ Código de comercio $/ \mathrm{COT}=$ Código orgánico de tribunales $/ \mathrm{CPC}=$ Código de procedimiento civil / CPR = Constitución política de la república / CTrab = Código del trabajo / CTrib = Código tributario / FRE = Federal Rules of Evidence de Estados Unidos de Norteamérica / ZPO = Zivilprozessordnung de Alemania.
} 
establecer la premisa fáctica de la sentencia. Hay que entenderla como una operación jurisdiccional que combina el conocimiento de la información probatoria y la decisión respecto a las cuestiones de hecho que integran la controversia. La mayor o menor relevancia de los parámetros epistémicos y jurídicos es algo que cada legislación debe precisar considerando los valores en juego en las disputas que se someten a resolución de los tribunales. De ahí que pueda afirmarse, como se hace en este trabajo, que la valoración probatoria no se encuentra sujeta únicamente a patrones epistemológicos y que -por igual razón- es incorrecto sostener que el modelo de las reglas de la sana crítica excluye por completo la presencia de criterios jurídicos de apreciación de evidencias.

Según la tesis que se defiende en este texto en el caso particular de los documentos públicos mercantiles, dada la intervención de fe pública en su confección, la valoración probatoria se integra en forma prevaleciente por criterios jurídicos. Usando terminología habitual podría decirse que corresponden a "pruebas legales", aunque -como se verá- resulta más adecuado afirmar que se trata de evidencias con una valoración en la que predominan parámetros legales.

Ahora bien, las necesidades de seguridad y eficiencia en el tráfico comercial exigen que la fe pública se ciña a cánones sencillos, ágiles y de bajo costo, lo que trae consigo dos consecuencias. Por una parte, los documentos provistos de fe pública mercantil deben generar efectos probatorios vinculantes para los jueces; por otra, esa eficacia se compone de técnicas legales que establecen soluciones normativas sobre suficiencia de la evidencia documental que siempre pueden ser derrotadas con flexibilidad. Esto se obtiene a través de métodos legales de valoración con contraprueba amplia que en el ordenamiento chileno aparecen expresados a través de fórmulas como "hacen fe", "hacen prueba", "se estará" y "deberá ponderar preferentemente", que difieren de la regla más rígida prevista en el art. 1700 CC ("hace plena $\left.f e^{\prime \prime}\right)$ pensada para instrumentos públicos sobre actos y contratos civiles. Dado que la doctrina y la jurisprudencia no han prestado mayor atención a estas materias, el propósito de los siguientes epígrafes es ofrecer una explicación dogmática respecto a un conjunto de disposiciones legales inspiradas en lo que podría llamarse una concepción probatoria de la fe pública mercantil y de los documentos utilizados en las relaciones de mercado, que se aparta del modelo establecido en el Código civil.

\section{Valoración probatoria. Significado y criterios aplicables}

\subsection{Valoración probatoria como actividad de juzgamiento fáctico}

La valoración de la prueba es una actividad de juzgamiento a través de la cual el juez determina si las evidencias producidas en un proceso otorgan suficiente confirmación a las alegaciones fácticas de las partes, y sobre la base de ello establece la premisa fáctica de la sentencia. Involucra un conjunto de operaciones intelectuales del juzgador encaminadas a comprender la información probatoria emanada de la evidencia producida en el proceso, analizar de manera crítica dicha información y ponderar su mérito con el objeto de adoptar una decisión en torno a los hechos discutidos ${ }^{1}$.

La valoración probatoria ha de inspirarse en el ideal del "saber-poder" propuesto por Ferrajoli, conforme al cual el juzgamiento hay que entenderlo como una combinación de conocimiento y decisión ${ }^{2}$. El conocimiento judicial de los hechos debe apoyarse en las probanzas allegadas a la causa y siempre tiene que ser sometido a un juicio crítico en lo que respecta a la calidad de la información. A su vez, para gozar de legitimidad la decisión jurisdiccional sobre los hechos se debe basar en ese conocimiento adquirido por el juez. Este ideal se condice con la norma fundamental del art. 76 inc. 10 CPR que califica a la potestad jurisdiccional como la facultad para "conocer" $y$ "resolver" las causas judiciales.

${ }^{1}$ SENTíS (1979), pp. 20-22; CABAÑAS (1992), pp. 31-36; DEVIS (2002), pp. 273 y 274; BONET (2009), pp. 237-239; NIEVA (2010), pp. 2735; MONTERO (2012), pp. 589-592.

${ }^{2}$ FERRAJOLI (1998), pp. 45 y 46. 
Corresponde a una actividad netamente jurisdiccional. Ya pasó el tiempo en el que se pretendía que el juzgador fuera sustituido por el legislador en la tarea de apreciar las pruebas y juzgar los hechos ${ }^{3}$. Esta última fue la concepción probatoria vigente en la época de la codificación decimonónica tributaria de una ideología sistemática-axiomática, que en cuanto a la valoración de evidencias propugnaba un método de soluciones normativas positivadas por el legislador de manera general y abstracta como única o principal alternativa ${ }^{4}$. La filosofía jurídica ha sido capaz de explicar con buenas razones que estas pretensiones de generalidad y abstracción son impracticables en el plano probatorio dada la naturaleza particular y cambiante que tienen los hechos. Ninguna prueba garantiza inexpugnablemente la verdad de la conclusión fáctica ${ }^{5}$.

Ahora bien, la sola circunstancia que esta actividad esté confiada al juez y recaiga sobre el material fáctico de una controversia no puede significar la desatención del conjunto de normas aplicables al caso, ni mucho menos autoriza a trazar una separación entre la esfera del Derecho sustantivo y el ámbito de la decisión judicial. La valoración de las evidencias, al igual que todo acto jurisdiccional, debe ejecutarse respetando el entorno institucional compuesto por normas sustantivas y procesales entre las cuales tiene que mediar una unión e interdependencia ${ }^{6}$. En otras palabras, el estudio de las particularidades de las evidencias debe realizarse en armonía con el contexto normativo que rodea la labor enjuiciadora de los tribunales. La advertencia planteada por Alex Stein en cuanto a la necesidad de mantener una comunión entre las normas sustantivas y la prueba judicial adquiere particular importancia para el tema que se analiza aquí. Según este autor la presencia de ámbitos no discrecionales en la legislación sustantiva impide abrir espacios de discrecionalidad judicial en los procesos, razón por la cual en tales situaciones el razonamiento probatorio tiene que respetar los parámetros previstos por el ordenamiento legal ${ }^{7}$. Esto implica, entre otras cosas, que la valoración de evidencias no puede ser entendida como una operación gobernada exclusivamente por cánones epistémicos ni orientada exclusivamente a la obtención de la verdad sobre los hechos. El entorno institucional en el que se desenvuelve exige considerar otros criterios y finalidades.

\subsection{Valoración probatoria como actividad de conocimiento de hechos en un contexto jurídico}

La valoración probatoria es una actividad orientada en primer lugar al conocimiento de hechos. El juez debe hacer un esfuerzo intelectual por aproximarse de la mejor manera posible a los hechos discutidos para adoptar una correcta decisión en el caso. Ningún sistema puede obviar esta dimensión de la actividad probatoria pues ello implicaría aceptar que la función jurisdiccional sea ejercida de espaldas a la realidad, lo que deslegitimaría al juzgamiento. Sería consentir en el indeseable fenómeno del "decisionismo procesal" donde las sentencias judiciales son nada más que la expresión de un acto de autoridad carente de fundamento cognoscitivo ${ }^{8}$.

El conocimiento judicial de los hechos se obtiene determinando el nivel de apoyo que brindan las evidencias a las hipótesis fácticas discutidas. Para tales efectos es necesario que los jueces examinen las pruebas y realicen un juicio de confirmación o corroboración (probabilidad lógica o inductiva) acudiendo a criterios epistémicos aceptados por la comunidad (máximas de la experiencia) o validados por una colectividad disciplinaria socialmente reconocida (conocimientos científicamente afianzados), y expliciten las razones de sus conclusiones en la

\footnotetext{
${ }^{3}$ CHIOVENDA (1922), pp. 313 y 314.

${ }^{4}$ TARUFFO (2002), pp. 390-393.

${ }^{5}$ FERRAJOLI (1998), p. 135.

${ }^{6}$ PÉREZ (2018), pp. 269-272.

7 STEIN (2013), pp. 251 y 252.

${ }^{8}$ FERRAJOLI (1998), pp. 42-44.
} 
sentencia (motivación del razonamiento judicial) ${ }^{9}$. En nuestra legislación los referidos criterios reciben la denominación de "reglas de la sana crítica" ${ }^{10}$.

Esta perspectiva de la valoración probatoria se relaciona con la finalidad epistemológica de la prueba procesal, es decir, con el propósito de lograr un establecimiento judicial de los hechos basado en datos empíricos con miras a la consecución de una verdad fáctica aproximativa o probabilística. Para un sector de la doctrina ésta sería la única dimensión válida en la tarea judicial de apreciar las pruebas, o dicho de otro modo la valoración probatoria sólo debería someterse a criterios de racionalidad empírica y siempre debería reconocer como única meta la obtención de la verdad sobre los hechos ${ }^{11}$.

Siendo acertado el planteamiento anterior en cuanto a la relevancia que tiene el contenido epistémico de la valoración probatoria, no parece correcto reducirlo al extremo de pensar que es la única dimensión aceptable. En primer lugar, porque el conocimiento judicial de los hechos no constituye un ejercicio exclusivamente epistemológico, y en segundo término pues todos los sistemas probatorios reconocen algún tipo de regulación jurídica de esta actividad.

En efecto, hay que tener presente que el esfuerzo intelectual que imprimen los jueces al valorar las evidencias se nutre de un conjunto de elementos inherentes al escenario dialéctico en el que se desarrolla esta operación y a la dimensión humana del juzgamiento. El juicio fáctico no es fruto de una actividad puramente epistémica; también intervienen aspectos argumentativos y psicológicos. El juez junto con conocer los hechos a través de la información empírica de las probanzas recibe versiones de las partes litigantes cargadas de argumentaciones y es destinatario del impacto de tales datos (dimensión persuasiva de la valoración), tiene que auscultar la sinceridad de las declaraciones de testigos (ámbito sometido a criterios de la psicología experimental) y debe interpretar los mensajes registrados por escrito en documentos (esfera perteneciente a la semiótica textual) ${ }^{12}$. Incluso más, en la hora actual el trabajo intelectual del juzgador puede conseguir refuerzos provenientes de otra inteligencia generada por programas informáticos con significativos niveles de precisión en algunos rubros ${ }^{13}$. Todo lo dicho deja de manifiesto que no cabe hablar de una única dimensión ni de una sola disciplina para la valoración probatoria. Es por definición una materia multidisciplinaria ${ }^{14}$.

Además, y en lo que resulta más pertinente a este estudio, es inconcebible pasar por alto que el conocimiento judicial de los hechos siempre debe ser ubicado en un entorno jurídico. Se hace muy difícil por no decir imposible encontrar algún ordenamiento legal que contemple en forma químicamente pura un modelo de valoración basado solo en pautas cognoscitivas. La denominada "prueba libre" o "libre valoración de la prueba" no constituye un modelo de Derecho positivo, como tampoco lo es la "prueba legal". Son más bien categorías teóricas carentes de consagración positiva en términos absolutos. Cualquier estudio sobre los sistemas probatorios contemporáneos deja de manifiesto que las soluciones son siempre el resultado de una combinación de criterios y estrategias para abordar la principal problemática que presenta la prueba en juicio, consistente en la minimización del riesgo de error en el juzgamiento fáctico de manera eficaz y eficiente ${ }^{15}$. Una clara demostración de lo anterior la ha ofrecido Damaška en su análisis del law of evidence, que en su opinión contempla reglas de corroboración probatoria aplicables en varios escenarios judiciales. Para este autor el common law, que por lo general ha sido mirado como el bastión de la prueba libre, nunca se ha opuesto a los instrumentos jurídicos destinados a restringir la libertad de valoración ${ }^{16}$.

\footnotetext{
${ }^{9}$ GASCÓN (2004), pp. 157-161; FERRER (2007), pp. 139-144; COLOMA Y AGÜERO (2014), pp. 685 y 691; GONZÁLEZ (2018), pp. 18-23.

${ }^{10}$ COLOMA Y AGÜERO (2014), pp. 685-692; MATURANA (2014), pp. 106-115 y 178-180.

${ }^{11}$ Con énfasis: TARUFFO (2002), pp. 387-403; FERRER (2007), pp. 45-47.

${ }^{12}$ Con referencia especial a los factores argumentativos y psicológicos: CABAÑAS (1992), pp. 37-39; NIEVA (2010), pp. 113-129 y 320-

332; CONTRERAS (2015), pp. 110-123; DE PAULA (2019), pp. 101-139.

${ }^{13}$ NIEVA (2018), pp. 79-98.

${ }^{14}$ NIEVA (2010), pp. 25, 95.

${ }^{15}$ ANSANELLI (2017), pp. 195-236.

${ }^{16}$ DAMAŠKA (2015), p. 34.
} 
Lo que ocurre es que, como ya se señaló, la apreciación de evidencias es una actividad cognoscitiva que se desenvuelve dentro de un marco jurídico y que -por lo mismo- es necesariamente permeable a patrones o puntos de vistas propios del Derecho. Así por lo demás lo reconoce la legislación nacional en diversas normas que combinan factores epistémicos y jurídicos en la valoración de probanzas.

Para el proceso civil el art. 428 CPC incluye ambas dimensiones al regular la valoración comparativa de los medios probatorios: "entre dos o más pruebas contradictorias, y a falta de ley que resuelva el conflicto, los tribunales preferirán las que crean más conformes con la verdad". Esta inclusión de factores epistémicos ("más conformes con la verdad") y jurídicos ("ley que resuelva el conflicto") ha llevado a nuestros autores a calificar el modelo probatorio civil como un sistema mixto ${ }^{17}$. Por su lado, la Corte Suprema ha señalado reiteradamente que la citada disposición "deja a la racional apreciación del juez determinar cuál de las pruebas opuestas se conforma más con la verdad, por lo que en esa valoración comparativa los jueces proceden con facultades propias y no están sujetos al control de casación", lo que equivale a asignar un contenido epistémico a la valoración; pero al mismo tiempo agrega que sí cabe una revisión casacional "si el conflicto debiera resolverse conforme a la preferencia establecida en un determinado texto legal", lo que implica incluir factores jurídicos que reciben la denominación genérica de "leyes reguladoras de la prueba"18.

La inclusión de categorías cognoscitivas y legales en la valoración también se encuentra presente en otras ramas del ordenamiento, como -por ejemplo- en los juicios laborales (art. 456 CTrab), los procedimientos ante Juzgados de Policía Local (art. 14 Ley № 18.287 de 1984), y las causas tramitadas ante Tribunales Ambientales (art. 35 inc. 10 Ley № 20.600 de 2012), donde el legislador admite expresamente que la valoración según las reglas de la sana crítica incluye la posibilidad de acudir a "razones jurídicas" en la apreciación de evidencias. En los procesos tributarios existe el mismo modelo (art. 132 inc. 13 CTrib) que además se complementa con dos reglas expresas sobre valoración de evidencias documentales: una recoge el principio "los actos solemnes se prueban a sí mismos" y otra establece una preferencia probatoria en favor de la contabilidad fidedigna (art. 132 inc. 14 CTrib). Esta última situación corresponde a un método legal de valoración según se verá más adelante (infra 5.2).

Finalmente, como marco referencial cabe tomar en cuenta las soluciones contenidas en el proyecto de reforma a la justicia civil que se inspiran en consideraciones equivalentes. El art. 295 del Proyecto CPC de 2012 consagra el método de las reglas de la sana crítica en combinación con soluciones jurídicas en tres sentidos: acepta que la ley atribuya un valor determinado a ciertas evidencias, tal como ocurre con la prueba documental (art. 306 del Proyecto); establece una restricción probatoria con respecto a las solemnidades de los actos jurídicos ("el acto o contrato solemne sólo puede ser acreditado por medio de la solemnidad prevista por el legislador") y, reconoce la fuerza normativa de las presunciones legales en el establecimiento de los hechos ${ }^{19}$.

\footnotetext{
17 PEÑAILILLO (1993), pp. 23-25; CORRAL (2018), p. 749. Entendiéndolo como un sistema de libre apreciación acompañado de reglas probatorias sobre procedencia y valoración: ANABALÓN (1954), p. 257. En sentido inverso, considerándolo un modelo de "prueba legal" con vigencia excepcional del sistema según reglas de la sana crítica: PALOMO (2014), p. 250.

${ }^{18}$ Corte Suprema, Rol № 4560-2014, de 15 de enero de 2015, considerando 6ㅇ. En igual sentido, junto a muchas otras sentencias: Corte Suprema, Rol № 21.762-1993, de 26 de junio de 1997, considerando 15; Corte Suprema, Rol № 6033-2006, de 24 de diciembre de 2007, considerando 5o; Corte Suprema, Rol № 5842-2010, de 1 de septiembre de 2010, considerando 13ㅇ; Corte Suprema, Rol № 60842011, de 4 de abril de 2012, considerando 110; Corte Suprema, Rol № 11.745-2011, de 5 de abril de 2012, considerando 50; Corte Suprema, Rol № 9047-2009, de 1 de junio de 2012, considerando 60; Corte Suprema, Rol № 3454-2012, de 21 de junio de 2012, considerando 9o; Corte Suprema, Rol № 7990-2009, de 11 de septiembre de 2012, considerando 15ㅇ; Corte Suprema, Rol № 45602014, de 15 de enero de 2015, considerando 6ㅇ; Corte Suprema, Rol № 92.849-2016, de 17 de agosto de 2017, considerando 13; Corte Suprema, Rol № 1747-2017, de 19 de abril de 2018, considerando 10 .

${ }^{19}$ Sobre la convivencia de "reglas de prueba legal" y "libre valoración de la prueba" en dicho modelo: HUNTER (2017), pp. 253-258.
} 


\subsection{Valoración probatoria como actividad integrada con la decisión jurisdiccional sobre los hechos}

La valoración probatoria es una actividad dirigida a la decisión jurisdiccional sobre los hechos. Su contenido no se agota en el estudio, comprensión y análisis de las evidencias; tiene además un componente decisorio consistente en la determinación de la suficiencia de las probanzas allegadas a la causa y, a partir de ello, el establecimiento de los sucesos discutidos. Los jueces valoran las pruebas para emitir un pronunciamiento sobre las cuestiones fácticas debatidas en un proceso, por lo que al momento de razonar en torno al material probatorio aportado lo hacen considerando necesariamente la resolución final. A eso se debe que la doctrina procesal vincule la valoración con el juicio fáctico: "la valoración de la prueba es una operación netamente enjuiciadora", afirma Jiménez Conde ${ }^{20}$.

Los partidarios de la teoría cognoscitivista de la prueba plantean la necesidad de distinguir entre la valoración de las evidencias y la decisión sobre los hechos, asignando a la primera una dimensión exclusivamente epistémica y a la segunda una connotación jurídica ${ }^{21}$. En tal sentido, Ferrer sostiene que la valoración probatoria solamente permite determinar el nivel de probabilidad que han alcanzado las alegaciones a partir del respaldo empírico dado por las evidencias, pero este juicio de corroboración no faculta al tribunal para adoptar una decisión sobre los hechos ya que para tales efectos se hace indispensable aplicar la respectiva regla legal de estándar. Sólo en esta última fase intervendrían los criterios jurídicos en el plano del juicio fáctico a través de las disposiciones sobre suficiencia probatoria (estándar), que determinan cuál es el grado de corroboración necesario para que el juez pueda dar por comprobadas las alegaciones de hechos ${ }^{22}$. Así, al valorar los jueces no decidirían sobre los hechos; se limitarían a preparar el material para luego resolver a partir de la confrontación o comparación entre el grado de corroboración determinado por la valoración y el nivel de suficiencia exigido por la ley mediante normas sobre estándar.

Siguiendo la misma línea argumental algunos afirman que en aquellos puntuales casos donde existen normas de "prueba legal", como sucede con la evidencia documental, lo que en realidad se está regulando no es la valoración sino la decisión acerca de los hechos. Es lo que piensa Hunter cuando explica la convivencia entre reglas probatorias y libre valoración en las causas civiles. Como apreciar la prueba consiste en medir el grado de apoyo que tiene una determinada hipótesis fáctica a la luz de la información que emana de la evidencia disponible, entonces -afirma- las normas legales sobre valoración sólo pueden concebirse como reglas de decisión y no propiamente como disposiciones jurídicas sobre apreciación probatoria ${ }^{23}$.

Las explicaciones precedentes son incompletas ya que al trazar una estricta división entre las operaciones que componen el juzgamiento sobre los hechos soslayan la interacción que siempre se produce entre ellas. Hay que tener presente que al momento de valorar las pruebas los jueces no prescinden de los criterios de suficiencia que establecen las reglas de estándar, sino por el contrario se guían por ellos; las normas sobre estándar probatorio, en efecto, no sólo establecen pautas para adoptar la resolución final sobre la cuestión fáctica, sino además -y en primer lugar- indican al juzgador lo que debe buscar en la prueba para poder después justificar su decisión ${ }^{24}$. Por lo mismo, cabe afirmar que lo que hacen los jueces al valorar es determinar la suficiencia probatoria de los elementos aportados al proceso con miras a la formulación de la premisa fáctica de la sentencia, lo que implica integrar la apreciación de evidencias a la cadena de operaciones que desarrollan los tribunales al decidir sobre los hechos ${ }^{25}$. Así pues, valoración

20 JIMÉNEZ (1978), p. 31. En igual sentido: SENTíS (1979), pp. 20-22; CABAÑAS (1992), pp. 34 y 35; DEVIS (2002), p. 304; BONET (2009), pp. 237-239; NIEVA (2010), p. 34; MONTERO (2012), pp. 589 y 590.

${ }^{21}$ TARUFFO (2010), pp. 184-190 y 246-254; FERRER (2007), pp. 45-49, 91-93 y 139-144; MONTERO (2017), pp. 91-95 y159-167; GONZÁLEZ (2018), p. 23.

22 FERRER (2007), pp. 45-49, 91-93 y139-144; FERRER (2013), pp. 28-37.

${ }^{23}$ HUNTER (2017), p. 253.

${ }^{24}$ GASCÓN (2005), pp. 129 y137.

${ }^{25}$ Para una buena explicación de esta cadena de operaciones: CARBONELL (2017), pp. 28-31. 
y decisión no constituyen momentos separados sino de actividades interrelacionadas, comprendiendo la primera una operación por medio de la cual el tribunal analiza y determina el peso de la información emanada de los medios producidos en el proceso, y la segunda el resultado final de tal operación.

A partir de la anterior consideración puede arribarse a otra conclusión importante para este estudio, relativa al sentido que tienen las normas legales que establecen criterios jurídicos de valoración probatoria. A diferencia de lo sostenido por la doctrina citada más arriba, resulta perfectamente explicable la presencia de reglas sobre apreciación de evidencias a través de las cuales la ley asigne o descarte suficiencia para dar por establecidos hechos, reglas que pueden inspirarse en parámetros no-epistémicos y apuntar a cumplir finalidades diversas a la obtención de la verdad. Puede decirse, así, que en estos casos las reglas y los criterios sobre valoración y estándar se encuentran unidos en un solo precepto, todo lo cual siempre hay que complementarlo con cánones adicionales que establezcan las exigencias que debe reunir la contraprueba para desvirtuar las soluciones normativas. Por consiguiente, es incorrecto afirmar que en las hipótesis de "prueba legal" las reglas de estándar serían innecesarias ${ }^{26}$. Lo que ocurre es que se comportan de distinta manera y operan en diversos planos: en una primera esfera conforman una unidad con los criterios de valoración probatoria y en un segundo ámbito establecen los requisitos para que una o más evidencias puedan destruir la solución prevista por la ley ${ }^{27}$. De ahí que resulte más acertado aludir a la prevalencia de criterios (epistémicos o jurídicos, según el caso) en lugar de contraponer las categorías conceptuales de "prueba libre" y "prueba legal".

\section{Prevalencia de criterios jurídicos en la valoración probatoria}

\subsection{En qué consiste}

Es el resultado de una decisión de política legislativa consistente en atribuir o denegar suficiencia probatoria a una evidencia mediante normas legales derrotables. Esto quiere decir que la ley determina ex ante la aptitud o insuficiencia de un medio de prueba para dar por demostrado un determinado suceso, sin perjuicio de la posibilidad de acreditar lo contrario.

Algunos ejemplos de normas legales sobre valoración probatoria en los que la ley asigna suficiencia a una evidencia son el art. 1700 CC respecto de los instrumentos públicos en materia civil, los arts. 35, 38 y 39 CCom en cuanto a los libros de contabilidad de los comerciantes, el art. 132 inc. $14^{\circ} \mathrm{CTrib}$ sobre contabilidad fidedigna y los arts. 1713 CC y 402 inc. 10 CPC relativos a la confesión judicial. También existen disposiciones que descartan suficiencia probatoria, como el art. 453 № 4 inc. 3 CTrab a propósito de la prueba ilícita en los juicios laborales y el art. 26 DL № 3475, de 1980 sobre timbres y estampillas aplicable a documentos mercantiles que no han pagado los tributos establecidos por dicho cuerpo normativo.

La presencia de criterios jurídicos de valoración probatoria presupone que el legislador ha identificado las hipótesis en las que militan razones que tornan aconsejable o necesaria la intervención del Derecho en esta actividad, teniendo presente las prioridades existentes en cada comunidad y las particularidades de las respectivas áreas de convivencia social ${ }^{28}$. Mediante la imposición de parámetros jurídicos de apreciación el sistema legal puede perseguir distintos objetivos a través de una pluralidad de técnicas. Como afirma un sector de la doctrina la injerencia del Derecho en el establecimiento judicial de los hechos puede orientarse a potenciar la calidad cognoscitiva de las evidencias o bien a proteger ciertos valores jurídicos relevantes para la comunidad aun en desmedro de la obtención de la verdad fáctica, a optimizar los costos asociados a los litigios judiciales y a repartir el riesgo de error fáctico entre las partes litigantes. Asimismo, estos objetivos pueden alcanzarse a través de una diversidad de estrategias como, por ejemplo, la regulación de la carga de la prueba, las exclusiones o preferencias de evidencias

\footnotetext{
${ }^{26}$ MONTERO (2017), p. 157.

${ }^{27}$ Piensa de esta manera, pero con la salvedad antes indicada: HUNTER (2017), pp. 256-258 y 264-268.

${ }^{28}$ WRÓBLEWSKI (2013), pp. 252-254 y 292-295.
} 
y la determinación del peso de algunos medios. Esta concepción es defendida en la actualidad por autores como Alex Stein, Bayón, Larroucau y Benfeld, y es compartida en el presente estudio. Esta corriente doctrinal sostiene -con acierto- que el razonamiento judicial sobre los hechos debe entenderse como algo que actúa entre dimensiones cognoscitivas y consideraciones de política jurídica, existiendo áreas particularmente propicias para la regulación normativa dado que los parámetros de la racionalidad epistémica resultan insuficientes ${ }^{29}$.

Las aclaraciones precedentes son indispensables para entender mejor el sentido que tiene la regulación legal de la valoración probatoria y la preferencia asignada a criterios jurídicos. En no pocas ocasiones el desprestigio que ha acompañado a la denominada "prueba legal" deriva de la falta de precisión acerca del real significado que tienen las disposiciones sobre apreciación de evidencias ${ }^{30}$. Así lo observaba Denti hace ya más de medio siglo a propósito de la eficacia legal de la prueba documental, indicando que este tema siempre debe ser examinado mediante la diferenciación de los tipos de regulación. En su parecer, afirmar que lo propio de la "prueba legal" es simplemente la vinculación jurídica a la que queda sometido el juez al valorar, es no manifestar nada significativo en torno a la naturaleza de esta institución, pues es posible hallar varios tipos de vínculos entre las pruebas y el resultado probatorio ${ }^{31}$.

Por lo mismo, resulta indispensable precisar cuáles son los objetivos perseguidos por las normas que imponen criterios jurídicos de valoración en cada situación e identificar correctamente las técnicas previstas para tales fines. No existe una única finalidad ni tampoco un solo método de regulación legal.

\subsection{Objetivos}

En términos generales puede afirmarse que el Derecho persigue cuatro grandes objetivos al momento de regular la prueba, algunos de los cuales son aplicables a la valoración de evidencias. El primero consiste en coadyuvar a la finalidad de buscar la verdad fáctica y de minimizar el riesgo de error en el juzgamiento sobre los hechos; un segundo objetivo es reducir los costos asociados a la actividad probatoria; el tercero es proteger otros valores tan relevantes como la consecución de la verdad; por último, el Derecho debe preocuparse de establecer estándares y cargas que permitan distribuir entre las partes el riesgo de error en el establecimiento de los hechos ${ }^{32}$.

Puede ser que estos objetivos sean compatibles y concurran simultáneamente en algunas normas legales sobre la prueba. En el ámbito de la valoración, donde las disposiciones asignan o privan suficiencia a algunas probanzas, los principales objetivos dicen relación con la protección de ciertos valores jurídicamente relevantes, la optimización de costos y la repartición del riesgo de error. Según se verá luego, en el caso de documentos públicos mercantiles las normas sobre suficiencia probatoria tienen por finalidad resguardar la seguridad de las relaciones de comercio y permitir a los empresarios y consumidores efectuar cálculos sobre el respeto de sus derechos, cumplimiento de las obligaciones y satisfacción de sus expectativas al menor costo posible; a la vez, las disposiciones imponen un reparto de riesgos de error entre los litigantes en relación con la contraprueba, ya que la imposición de criterios legales en el valor de evidencias documentales siempre determina estándares de suficiencia que debe satisfacer la parte que pretende desvirtuar la solución normativa. Puede decirse son dos caras de la misma medalla, ya que a cada medida jurídica sobre suficiencia probatoria la acompaña una regla de estándar y carga para lograr desvirtuarla.

${ }^{29}$ STEIN (2005), pp. 107, 108 y 118-140; STEIN (2013), pp. 252-255; BAYÓN (2008), pp. 18-21; LARROUCAU (2018), pp. 124-133; BENFELD (2018a), pp. 172-175.

${ }^{30}$ Con visiones particularmente críticas, pero incompletas: SENTís (1979), pp. 120-126; DEVIS (2002), pp. 274 y 275; TARUFFO (2002), pp. 396-401; FERRER (2005), pp. 44-48.

${ }^{31}$ DENTI (1957), pp. 47-49.

${ }^{32}$ BAYÓN (2008), pp. 19 y 20. 
Podría ser que alguna regla de valoración procure contribuir a la obtención de la verdad fáctica, tal como lo ha sugerido recientemente González Lagier al referirse a las "inferencias normativas con fundamento empírico" ${ }^{33}$ o como lo ha postulado Benfeld al aceptar la inclusión de indicaciones o restricciones normativas dentro de las "reglas de la sana crítica" ${ }^{34}$. No es, sin embargo, un tema que se abordará en este lugar atendida la orientación exclusivamente jurídica que tienen las normas de apreciación de los documentos empleados en el tráfico comercial. Esto mismo permitirá refutar las críticas que se han dirigido contra la justificación de tales disposiciones, en las que se asume que los preceptos estarían estableciendo generalizaciones basadas en criterios epistémicos. Hay aquí un manifiesto error. Como se podrá explicar, las reglas legales de valoración de estas pruebas documentales no se apoyan en cánones empíricos de normalidad o frecuencia (id quod prelumque accidit), sino en factores de estricto contenido jurídico (infra 4.2).

\subsection{Técnicas legales con contraprueba amplia y con contraprueba limitada}

Pueden distinguirse dos grupos de técnicas legales a través de las cuales se imponen criterios jurídicos de valoración de evidencias. Dependiendo de la mayor o menor rigidez para lograr desvirtuar la solución prevista en la ley cabe hablar de una modalidad con contraprueba amplia y otra con contraprueba limitada ${ }^{35}$.

Hay que aclarar que cualquiera sea el método usado por el legislador es indispensable que siempre se considere la opción de desvanecer la solución normativa mediante prueba en contrario. En primer lugar, es la única manera de armonizar esta opción legislativa con la finalidad cognoscitiva de la prueba, que si bien puede quedar supeditada a la consecución de otros objetivos no puede ser completamente eliminada. Concluir lo contrario implicaría aceptar que el Derecho contempla hipótesis en las que la decisión judicial renuncia en términos absolutos a la reconstrucción empírica de los hechos, lo que es insostenible. Como ya se dijo, el punto de partida de cualquier sistema probatorio debe ser siempre el conocimiento de los hechos, lo que en el tema en estudio sólo se logra aceptando la posibilidad de desvirtuar las soluciones previstas por el legislador, pues así como el contenido de la valoración probatoria no es exclusivamente epistémico tampoco puede ser puramente normativo. Un segundo fundamento se vincula con el derecho a la prueba como elemento integrante de la garantía del debido proceso legal, de acuerdo con el cual las partes siempre deben tener la posibilidad de aportar probanzas tendientes a contradecir las conclusiones fácticas establecidas por normas legales. Impedirlo significaría afectar en su base esta garantía y haría inconstitucional cualquier precepto que lo establezca. El procesalismo italiano ha sido enfático en estos puntos y ha adoptado así la acertada posición de eliminar el concepto de "pruebas legales absolutas" que hasta hace algunas décadas era aceptado ${ }^{36}$.

En nuestro país esta tesis de la derrotabilidad ha sido defendida por Hunter aunque con una connotación que resulta demasiado reduccionista, ya que desde su punto de vista solamente cabría admitir un método de "prueba legal" que califica como reglas de presunciones legales relativas y de carga probatoria ${ }^{37}$. Esta materia debe abrirse a una pluralidad de opciones precisamente por recaer sobre un campo multifacético y variable como lo es el de la prueba en juicio. El mismo autor reconoce que este asunto entraña un problema de política jurídica y siendo así debe aceptarse que el legislador establezca una gradación de técnicas a partir de la mayor o menor trascendencia que asigne al bien jurídico protegido por la norma de valoración.

33 GONZÁLEZ (2014), pp. 88 y 97; GONZÁLEZ (2018), pp. 25 y 26.

${ }^{34}$ BENFELD (2018a), pp. 175-182; BENFELD (2018b), pp. 99-102 y 108-110.

35 LOMBARDO (1992), pp. 621 y 622. Con otra denominación: LOMBARDO (1999), pp. 564 y 565; CANESTRELLI (2010), p. 62; DI FAZZIO (2018), pp. 292 y 293.

${ }^{36}$ Sobre el carácter esencialmente controvertible de la "prueba legal": LOMBARDO (1992), pp. 620 y 621; LOMBARDO (1999), pp. 552554; IACOBONI (2006), pp. 33-37; CANESTRELLI (2010), pp. 62 y 63; DI FAZZIO (2018), pp. 292 y 293. Aceptando la existencia de "pruebas legales absolutas": FURNO (1954), pp. 166-171.

${ }^{37}$ HUNTER (2017), pp. 256-258. 
Lo indispensable es que la ley permita la prueba en contrario, pero las estrategias que se utilicen al respecto pueden ser múltiples.

Existe un primer grupo de técnicas legales de valoración que contemplan una contraprueba amplia, donde la solución probatoria establecida por la ley puede ser desvirtuada con cualquier tipo de evidencia aportada al proceso, siempre y cuando satisfaga el estándar previsto al efecto o supere la preferencia asignada por la norma. Lo importante es que en el proceso exista prueba con aptitud para refutar la solución legal, situación en la cual el juez quedará autorizado para prescindir de la medida normativa de valoración y podrá resolver la controversia de acuerdo con el mérito de la información proporcionada por el material probatorio allegado a la causa ${ }^{38}$. La contraprueba puede consistir en medios cuya valoración se someta a otros parámetros jurídicos o a criterios epistémicos sujetos a estándares generales 0 especiales, lo que dependerá de lo señalado por la regla legal ${ }^{39}$. Lo determinante es que bajo esta modalidad resulta perfectamente factible que el tribunal desestime la solución jurídica apreciando comparativamente las probanzas allegadas al proceso, asignando mayor fuerza a las conclusiones emanadas de la información que otorgan tales elementos para así apartarse de la valoración legal. De este modo, por ejemplo, si la ley establece una preferencia en favor de una evidencia para la determinación de un hecho, el tribunal puede arribar a una decisión diferente mediante el análisis de la totalidad de las evidencias o bien de la confrontación de unos medios con otros. Según se indicará, este método se encuentra presente en el ordenamiento nacional en normas relativas a pruebas documentales del tráfico negocial cuya suficiencia aparece descrita con fórmulas como "hacen fe", "hacen prueba", "se estará" y "deberá ponderar preferentemente" (infra 5.2).

El otro grupo está integrado por técnicas de valoración con contraprueba limitada en las que se intensifica la solución normativa al hacer más exigente la posibilidad de rendir prueba de refutación. En este método la atribución o denegación de suficiencia probatoria solamente puede ser desvirtuada en la medida que la parte afectada formule un procedimiento especial de impugnación de la solución normativa y aporte evidencia idónea que demuestre el o los motivos de la objeción, o bien se exige la producción de una determinada prueba con exclusión de otras. Esto implica que el tribunal tiene el deber de aplicar las normas de valoración aun cuando en la causa existan pruebas en contrario, ya que solamente estará autorizado a resolver en sentido distinto en la medida que la parte interesada haya impetrado formalmente un procedimiento de impugnación, que podrá tramitarse en el mismo proceso o en otro diferente según determine la ley; lo que incluso puede quedar reforzado con restricciones adicionales como ocurre con el principio "los actos solemnes se prueban a sí mismos" (art. 1701 inc. 1ㅇ CC; art. 132 inc. 14은 CTrib), o con exigencias legales específicas como en la objeción de la autenticidad de las escrituras públicas regulada por el art. 429 CPC o en la impugnación de la veracidad de la declaración de pago de precio en las escrituras públicas sobre compraventas (art. 1876 inc. 2은 $(\mathrm{CC})^{40}$. Es improcedente entonces acudir al expediente de la apreciación comparativa de los medios probatorios que está permitido en la otra técnica, de tal suerte que si no existe el procedimiento formal de impugnación o si en éste no se ha producido prueba suficiente el juez tiene el imperativo de apreciar las evidencias con estricta sujeción a los criterios jurídicos impuestos por la ley.

Esta técnica se encuentra presente en la regla del art. 1700 CC respecto al valor de "plena $f e$ " de los instrumentos públicos civiles, que -como se explicará- difiere de la regla del art. 129 CCom en cuanto al valor probatorio de la veracidad de las escrituras públicas que contienen actos y contratos mercantiles ${ }^{41}$. Como lógica consecuencia de una distinta concepción de la fe

\footnotetext{
38 LOMBARDO (1992), p. 621.

${ }^{39}$ Una buena explicación de estas opciones en HUNTER (2017), pp. 262-268.

${ }^{40}$ Sobre este tipo de limitaciones probatorias: LOMBARDO (1992), p. 622.

${ }^{41}$ Otro caso donde se emplea esta técnica es el de la confesión judicial prestada en juicios civiles, que de acuerdo con los arts. 1713 CC y art. 402 CPC tiene valor de plena prueba que únicamente puede ser dejado sin efecto mediante una retractación basada en error de hecho que debe ser demostrado en la causa.
} 
pública en las actividades de comercio, el método legal aplicable a estos documentos es más flexible que el establecido para los instrumentos sobre actos jurídicos civiles (infra 5.3).

\section{Valoración probatoria de los documentos públicos mercantiles con prevalencia de criterios jurídicos. Fundamento, objetivos y técnicas legales de regulación}

\subsection{Fundamento: la fe pública mercantil}

Los documentos públicos mercantiles son evidencias en las que prevalecen criterios jurídicos de valoración en virtud de la fe pública concurrente ${ }^{42}$. Su apreciación probatoria debe estar supeditada en primer término a las soluciones normativas previstas por el legislador y sólo en caso de que existan probanzas en sentido contrario cabe aplicar cánones epistémicos. El fundamento de esta solución legal es netamente jurídico y se sustenta en los elementos propios de la fe pública que garantizan la autenticidad y fidelidad de la información documentada ${ }^{43}$.

El primer elemento de la fe pública es el conjunto de normas legales y reglamentarias que disciplinan la actividad documentadora. La doctrina notarialista lo califica como "rito instrumental", que incluye una serie de exigencias formales que deben respetarse para producir documentos premunidos de garantías ${ }^{44}$. En la fe pública documental que interviene en el tráfico negocial es posible hallar dos modalidades de regulación: una que se concentra en la intervención de fedatarios en la documentación de actos y contratos, y otra que se apoya en el cumplimiento de formalidades relativas a la confección y conservación de documentos. La primera opción se condice con la perspectiva normativo-subjetiva de la fe pública documental y un ejemplo paradigmático es la escritura pública en cuya autorización y custodia interviene el notario (art. 1699 inc. 2ㅇ CC, art. 403 COT). La segunda alternativa se identifica con la concepción normativo-objetiva de esta institución que en la legislación nacional aparece recogida en disposiciones como las que regulan los documentos electrónicos suscritos mediante firma electrónica avanzada (arts. 2o g, 12 e, 17-22 Ley № 19.799, de 2002; arts. 13-27, 30, 32 inc. 2으 Decreto Supremo № 181 Ministerio de Economía, Fomento y Reconstrucción, de 2002) ${ }^{45}$.

En el caso de la fe pública mercantil el conjunto normativo se ciñe a parámetros de sencillez, agilidad y bajo costo para así lograr una mayor funcionalidad en el tráfico, lo que permite distinguirla de la fe pública notarial prevista para los actos y contratos civiles que incluye exigencias más rígidas ${ }^{46}$. El Derecho comercial es en esencia antiformalista y por ello los requisitos impuestos a la documentación de operaciones mercantiles siempre deben presentar algún grado de flexibilidad para adaptarse a la movilidad y velocidad de las relaciones entre empresarios y consumidores ${ }^{47}$. A esto se debe que en la literatura jurídica española Uría se manifestara partidario de dar un trato "más liberal y menos rígido" a la dación de fe pública ${ }^{48}$, que Gutiérrez del Solar haya señalado que la rapidez del comercio exige una menor atención del "principio de solemnidad" que integra la fe pública ${ }^{49}$, y que Fugardo exponga que la fe pública mercantil siempre debe considerar una "flexibilidad formal" que se traduce en una mayor libertad del proceso de formación documental y la subsecuente posibilidad de que los fedatarios certifiquen documentos redactados por las propias partes sin su asesoría ${ }^{50}$.

El segundo elemento es el valor jurídico y probatorio que confiere esta institución legal a los documentos usados en el tráfico, sustentado en las garantías que brinda la regulación recién

\footnotetext{
${ }^{42}$ Identificando a la fe pública como el fundamento de las normas legales de valoración probatoria de los documentos públicos, entre muchos otros: NÚÑEZ (1986a), pp. 331-337; COUTURE (1989), pp. 83-88; RODRÍGUEZ (1996), p. 176; ROJAS (2003), pp. 134 y 135; LUIS (2008), p. 49; SERRA (2009), p. 240; DI FAZZIO (2018), pp. 124-126. En igual sentido respecto a la fe pública mercantil: FORNIÉS (1975), p. 23; GUTIÉRREZ DEL SOLAR (1982), p. 256; FUGARDO (1999), pp. 23 y 98.

${ }^{43}$ MENESES (2018), pp. 194-208, con la discusión bibliográfica ahí contenida.

${ }^{44}$ PELOSI (2006), pp. 179-181.

${ }^{45}$ Sobre estas perspectivas de la fe pública documental: MENESES (2018), pp. 186-192 y 194-198.

${ }^{46}$ URÍA (1970), pp. 134-136; FORNIÉS (1975), pp. 29-43; PRÍES (2016), pp. 159-165.

47 JEQUIER (2013), p. 13

${ }^{48}$ URÍA (1970), p. 148.

${ }^{49}$ GUITÉRREZ (1982), p. 278.

${ }^{50}$ FUGARDO (1999), p. 31. Con matices en virtud de las reformas introducidas a la legislación notarial de España a partir de diciembre de 1999: FUGARDO (2007), pp. 163-169, 176 y 177.
} 
descrita, especialmente intensas en lo relativo a la autenticidad. Los autores han alcanzado relativo consenso en torno a estos efectos vinculantes. Entre los notarialistas y publicistas este aspecto de la fe pública ha sido descrito como el valor que la ley asigna a un documento que permite asegurar el desenvolvimiento de las relaciones jurídicas y que se proyecta en el campo de la prueba mediante reglas de apreciación obligatorias para el juez ${ }^{51}$. En la dogmática penal ha sido identificado con los efectos jurídicos de obligatoriedad general que la ley atribuye a ciertos objetos en virtud de los cuales el tráfico puede desarrollarse de manera armoniosa y pacífica ${ }^{52}$. La jurisprudencia nacional se ha manifestado en forma parecida al decir que la fe pública se relaciona con "la seguridad y normalidad del tráfico jurídico, concepto este que se halla ligado estrechamente a la autenticidad de determinados elementos a los cuales la ley ha atribuido ciertos efectos de obligatoriedad general, en especial, la producción de confianza en la genuinidad de ellos" ${ }^{53}$.

Existe una directa vinculación entre la regulación de la actividad documentadora (primer contenido de la fe pública) y la eficacia jurídico-probatoria que la ley atribuye a los documentos extendidos con cumplimiento de dicha regulación (segundo contenido de la fe pública). Incluso más, puede establecerse una relación directamente proporcional ya que mientras más rigurosas son las exigencias aplicables a la documentación de negocios mayor puede ser el valor de estos elementos; a la inversa, con requisitos menos estrictos la eficacia jurídica y probatoria debe ser más flexible ${ }^{54}$.

\subsection{Objetivos: seguridad y eficiencia en el tráfico mercantil}

La prevalencia de criterios jurídicos en la valoración probatoria de los documentos públicos mercantiles tiene por finalidad lograr una correlación entre los niveles de seguridad y eficiencia que alcanza el tráfico negocial en virtud de la fe pública, y los cánones a los que debe someterse la decisión judicial de controversias sobre actos, contratos y operaciones de comercio. Las garantías que ofrece la regulación de la actividad documentadora favorecen el desarrollo de los negocios y permite a las partes efectuar cálculos sobre el cumplimiento de los acuerdos, las utilidades que podrán alcanzarse y la satisfacción de las expectativas económicas ligadas a las operaciones mercantiles, todo lo cual debe recibir un trato equivalente en los procesos judiciales donde se discuten los términos y alcances de tales pactos.

La fe pública es una institución concebida para dar seguridad y eficiencia a los negocios y la economía ${ }^{55}$. La presencia de canales confiables de transmisión de información comercial y de almacenamiento de acuerdos contractuales permite a los empresarios y consumidores actuar bajo parámetros claros, lo que tiene suma importancia para alentar el tráfico mercantil. Las previsiones normativas proporcionan un marco regulatorio apropiado para que los contratantes realicen inversiones y adquieran bienes y servicios de manera expedita y con perspectivas de utilidades calculables sobre la base de la información disponible ${ }^{56}$. Cuando las partes contratantes deciden consignar sus acuerdos negociales en documentos provistos de fe pública lo hacen con un evidente sentido práctico, consistente en la conveniencia de dejar constancia fidedigna del contenido de los pactos celebrados para así evitar futuras discusiones y, en su caso, reducir los costos que generan los litigios judiciales gracias al uso de datos auténticos y creíbles. Bentham hablaba de la "fuerza antilitigiosa" de las evidencias preconstituidas para así explicar cómo las garantías que rodean a los registros documentales de los contratos producen un efecto disuasorio para las partes y simplificador para el juez a la hora de resolver el conflicto ${ }^{57}$. Por las

\footnotetext{
51 NÚÑEZ (1986a), pp. 331-337; NÚÑEZ (1986b), pp. 458-464; RODRÍGUEZ (1996), p. 176; ROJAS (2003), pp. 134 y 135.

52 ETCHEBERRY (1961), pp. 56-62; GARRIDO (2008), p. 14.

53 Corte de Apelaciones de San Miguel, Rol № 863-1996, de 3 de mayo de 1996, considerando 9․

${ }^{54}$ MENESES (2017), p. 102.

${ }^{55}$ GÓMEZ (1977), p. 35; GUTIÉRREZ DEL SOLAR (1982), p. 272; FUGARDO (1999), pp. 23, 30 y 31; HUIDOBRO (2010), p. 259; PRÍES (2016), pp. 82,110 y 160.

56 PEÑAILILLO (2009), p. 57; ISLER (2019), pp. 207-211.

${ }^{57}$ BENTHAM (1971), pp. 235 y 236.
} 
mismas razones en el último tiempo se hace referencia a la "función antiprocesal" de los documentos dotados de fe pública o a la "función de justicia preventiva" que corresponde cumplir al notariado al intervenir en la documentación de relaciones contractuales ${ }^{58}$. No cabe duda que la fe pública vigoriza el factor informacional que es fundamental para el desenvolvimiento del tráfico y para lograr resultados eficientes en los procesos jurisdiccionales, tanto para que las partes puedan definir con claridad sus posiciones y expectativas de éxito en los asuntos litigiosos como para que los tribunales puedan dictar sentencias con bajo riesgo de error y poco desgaste de tiempo y $\operatorname{costos}^{59}$.

Esta es la justificación de las normas sobre suficiencia probatoria de los documentos públicos mercantiles, ya que la única manera de alcanzar las antedichas finalidades es fijando cánones normativos a los que debe someterse el razonamiento judicial sobre los hechos. Los cálculos y proyecciones que efectúan las partes al documentar sus acuerdos comerciales deben replicarse en las discusiones procesales, para lo cual es indispensable que la ley fije criterios que indiquen el mérito probatorio de la evidencia documental. De lo contrario las previsiones normativas perderían su fuerza en el proceso y la eficacia que tiene la fe pública en el tráfico se desvanecería por la sola circunstancia de iniciarse una causa judicial. Tiene razón Alex Stein cuando protesta contra la inconsistencia que se produce cuando la no discrecionalidad del Derecho sustantivo es seguida por una discrecionalidad en el establecimiento judicial de los hechos ${ }^{60}$. No puede existir un divorcio entre las relaciones sustantivas y las sentencias de los tribunales porque ello abre espacios de incertidumbre y, finalmente, de injusticia. Al revés, lo que tiene que ocurrir es que las soluciones contempladas por la ley para las relaciones de Derecho sustantivo alcancen un desarrollo y complemento mediante las decisiones jurisdiccionales adoptadas en sede procesal ${ }^{61}$.

Ahora bien, todo lo expuesto con anterioridad sólo tiene sentido en la medida que se asigne un contenido rigurosamente jurídico al fundamento y los objetivos de la imposición de criterios legales de valoración de los documentos públicos mercantiles, lo que no siempre es asumido con claridad. Varios autores han planteado que las normas legales sobre apreciación de pruebas documentales se inspirarían en criterios cognitivos y por ende contribuirían al correcto establecimiento judicial de los hechos ${ }^{62}$. En su teoría sobre la "prueba legal" Furno fue categórico al momento de referirse al significado empírico que tendrían las normas de valoración de documentos públicos, afirmando que ellas se justificarían en la circunstancia de que "es normal que el documentador público testimonie fielmente la verdad en los instrumentos que autorice" ${ }^{63}$. Concordando con este postulado teórico Jiménez Conde ha dicho que las reglas legales de apreciación estarían diseñadas para descubrir la verdad histórica de los sucesos discutidos en una causa, teniendo como fundamento "criterios de uniformidad" o de "normalidad jurídica" (id quod prelumque accidit) ${ }^{64}$.

Este planteamiento es errado. Cappelletti lo aclaró bien al señalar que las normas legales de valoración de documentos públicos persiguen finalidades prácticas de seguridad de las relaciones jurídicas que ameritan preferencia respecto a la verdad de los hechos ${ }^{65}$. En la doctrina nacional Hunter se ha manifestado en igual sentido ${ }^{66}$. El fundamento es, pues, jurídico y no epistémico, por lo que las críticas que se han dirigido en contra de la racionalidad de estas reglas apuntan en la dirección equivocada. Se ha señalado que es empíricamente falso que en todos los casos en los que se extiende un documento público se declara verdaderamente la fecha del

\footnotetext{
${ }^{58}$ DI FAZZIO (2018), pp. 5, 6, 125 y 126.

${ }^{59}$ Sobre el factor informacional y la utilización de criterios de análisis económico del Derecho en la prueba: STEIN (2005), pp. 136 y 137; JIMÉNEZ Y FOUILLIOUX (2018), pp. 144-147.

${ }^{60}$ STEIN (2015), p. 252.

${ }^{61}$ PÉREZ (2018), p. 272.

62 Junto a muchos otros: FURNO (1954), pp. 174-176; JIMÉNEZ (1978), pp. 54-62; LOMBARDO (1999), pp. 543-554; IACOBONI (2006), pp. 33-36; CANESTRELLI (2010), pp. 56-58; COMOGLIO (2010), pp. 150 y 151; MONTERO (2012), pp. 598-600.

${ }_{63}$ FURNO (1954), p. 175.

64 JIMÉNEZ (1978), p. 56

${ }^{65}$ CAPPELLETTI (2002), pp. 272-277.

${ }^{66}$ HUNTER (2017), p. 265. Véase también: MENESES (2017), pp. 167-176, con discusión bibliográfica.
} 
otorgamiento $u$ otros aspectos previstos por normas legales ${ }^{67}$. El punto aquí es otro. La regla legal que asigna fuerza probatoria a un documento público no se apoya en ese criterio cognoscitivo sino en la ya referida razón jurídica. Su racionalidad no es empírica sino práctica: es algo que necesita el tráfico negocial para lograr un desarrollo sano y eficiente, que por eso mismo es impuesto por el Derecho mediante la institución de la fe pública y sus efectos.

En relación con lo anterior, es necesario señalar que en este trabajo se entiende que el juzgamiento fáctico no puede desarrollarse al margen de los valores jurídicos a los que una comunidad asigna preferencia. Si bien es cierto -amerita repetirlo- que el razonamiento judicial sobre los hechos no puede realizarse de espaldas a la realidad, es igualmente cierto que tampoco puede hacerlo de espaldas a valores considerados importantes en una sociedad. En tal sentido puede afirmarse que la imposición de criterios jurídicos de valoración de evidencias documentales permite robustecer el cuadro axiológico de la actividad probatoria, añadiendo a la verdad fáctica otros valores y finalidades igualmente atendibles e importantes para el ordenamiento ${ }^{68}$. Esto explica la razón por la cual las normas legales sobre valoración pueden ser concebidas como un conjunto coherente de elementos de juicio junto con las reglas de la sana crítica ${ }^{69}$. Hasta podría plantearse que constituyen una medida que fortalece la legitimidad y corrección de las decisiones jurisdiccionales, ya que una correcta solución axiológica favorece siempre una mejor solución judicial ${ }^{70}$.

\subsection{Técnicas legales de valoración con contraprueba amplia, con énfasis en la autenticidad documental}

El método legal de valoración con contraprueba amplia es el corolario de todo lo expuesto, porque la única manera de lograr un equilibrio entre el dinamismo de los negocios comerciales y la seguridad y eficiencia en el tráfico es fijando parámetros normativos dúctiles sobre apreciación probatoria. A la flexibilidad de la fe pública mercantil la debe seguir una ductilidad en las soluciones jurídicas sobre valor de la evidencia documental, lo que se obtiene a través de técnicas que admitan de manera fluida la prueba en sentido contrario. Estas técnicas imponen al juzgador el deber de asignar o restar peso probatorio a los documentos públicos mercantiles y, por consiguiente, de dar por establecidas o no establecidas las circunstancias de hecho indicadas en la disposición legal, a menos que en la causa se produzca prueba capaz de desvirtuar tales soluciones normativas.

En esta materia es posible hallar alternativas y combinaciones en dos ámbitos.

El primero se refiere al específico método empleado por el legislador para regular la valoración de esta evidencia documental, siendo los más utilizados las normas de presunción legal relativa y las reglas de preferencia probatoria. Las notas definitorias de estos u otros mecanismos aún no han sido desarrolladas por la doctrina nacional, sin perjuicio de lo cual puede señalarse que el principal elemento distintivo dice relación con los estándares probatorios para superar las soluciones normativas establecidas en cada caso, que siempre serán mayores en el caso de las presunciones iuris tantum ${ }^{71}$. Algo de esto se verá en el siguiente apartado a propósito de algunas normas vigentes en nuestro ordenamiento.

El otro ámbito dice relación con los extremos del documento que quedan cubiertos por la norma de valoración, que pueden circunscribirse a su aspecto externo (autenticidad) o incluir también el ámbito interno (veracidad del contenido). La opción que adopte el legislador debe inspirarse en una multiplicidad de factores relacionados con las exigencias asociadas a la fe

\footnotetext{
${ }^{67}$ FERRER (2005), p. 46.

68 Sobre el punto: SUMMER (1999), pp. 510 y 511; BAYÓN (2008), pp. 18, 20, 33 y 34; WRÓBLEWSKI (2013), pp. 248-254 y 292-296; GARCÍA (2014), pp. 51 y 57; DAMAŠKA (2015), p. 125; HUNTER (2017), pp. 253-256; BENFELD (2018a), pp. 178-181; GONZÁLEZ (2018) pp. $25,26,31$ y 32 .

${ }^{69}$ Es la tesis de BENFELD (2018a), pp. 175-182; BENFELD (2018b), pp. 99-102 y 110-112. Es una alternativa que plantea con reservas COLOMA (2018), pp. 145-149.

${ }^{70}$ CARBONELL (2017), pp. 7, 8, 29 y 30

71 Una propuesta en HUNTER (2017), pp. 262-268.
} 
pública mercantil y las necesidades del tráfico negocial, debiendo mantenerse siempre una proporcionalidad entre ellos. Hay que tener presente que la fe pública documental es por definición una institución sometida a escalas de valores que la ley determina sobre la base de los referidos elementos y que, por lo mismo, admite gradaciones ${ }^{72}$. Como consideración general cabe mencionar el ya referido principio según el cual mientras más rigurosas sean las exigencias asociadas a la dación de fe pública (vgr. estricto sometimiento a solemnidades de la actividad documentadora, intervención de fedatarios con funciones de asesoramiento a las partes, revisión por los ministros de fe de la juridicidad de los actos documentados, etc.) más intensos pueden ser los efectos jurídicos y probatorios asignados a los documentos, y viceversa ${ }^{73}$.

En lo que respecta a los documentos provistos de fe pública mercantil la solución teórica más invocada consiste en asignar un valor de presunción legal iuris tantum a la dimensión externa de esta evidencia (autenticidad). En la doctrina española, Uría indicaba que la dación de fe pública establece una presunción legal respecto de la existencia de todo o parte del acto documentado, lo que permite tenerlos por auténticos y ciertos mientras no se pruebe lo contrario $^{74}$. En términos equivalente Forniés propuso definir la fe pública mercantil como una presunción iuris tantum de autenticidad de los actos jurídicos almacenados en documentos propios del tráfico ${ }^{75}$. Fugardo la ha entendido como una función del Estado cuyo objeto es robustecer los actos y negocios mercantiles con una presunción de eficacia, aludiendo de este modo primordialmente a la perspectiva externa de los documentos usados en el comercio ${ }^{76}$.

Si se revisa bien el contenido de la fe pública mercantil se podrá comprobar que el centro de gravedad de la eficacia jurídica y probatoria de esta institución dice relación con la genuinidad de los documentos empleados en las relaciones de comercio, que es -en efecto- el atributo que necesitan estos elementos para canalizar información relevante sobre negocios jurídicos. Así fue en sus orígenes históricos y se mantiene hasta hoy ${ }^{77}$. Como ya se dijo, el legislador puede adoptar medidas encaminadas a potenciar los efectos de la fe pública y de esta manera aumentar el valor de las evidencias documentales. Es lo que ha ocurrido en el Derecho español tras las reformas legislativas introducidas al notariado y a la dación de fe pública mediante la intervención de pólizas mercantiles ${ }^{78}$. Así y todo puede afirmarse que lo fundamental sigue siendo el aspecto externo de los documentos mercantiles, que constituye un mínimo imprescindible para que la documentación de operaciones comerciales cumpla la función de almacenar acuerdos de manera clara y fidedigna.

Sobre el punto hay que tener presente que la autenticidad corresponde al primer atributo de credibilidad de esta evidencia, por lo que su fortalecimiento permite vigorizar el mérito final. No por nada la doctrina probatoria la ha caracterizado como "el elemento más importante de la credibilidad de la prueba tangible", al tratarse de un rubro que permite dilucidar si la evidencia es lo que parece ser ${ }^{79}$. En este orden de cosas resulta bastante claro que el establecimiento $a b$ initio de esta cualidad constituye la principal fortaleza que presenta este medio probatorio en comparación con los documentos privados ${ }^{80}$. "Acta probant se ipsa" como se señalaba en la doctrina francesa para destacar el mérito de estos elementos, lo que quiere decir que los documentos públicos se prueban a sí mismos sin que quepa exigir la presencia de otras probanzas para acreditar su genuinidad como continente de información fáctica ${ }^{81}$. El documento privado, en cambio, al no estar provisto de fe pública carece per se de mérito probatorio a menos que su autenticidad sea debidamente demostrada en juicio, lo que en la legislación nacional se

\footnotetext{
${ }^{72}$ NÚÑEZ (1986 b), p. 461.

73 MENESES (2017), p. 102

${ }^{74}$ URÍA (1970), p.135.

75 FORNIÉS (1975), pp. 23 y 47

${ }^{76}$ FUGARDO (1999), p. 23.

77 URÍA (1970), pp. 122, 135 y 136; FORNIÉS (1975), pp. 23, 24, 40 y 47; GÓMEZ (1977), pp. 32-35; GUTIÉRREZ DEL SOLAR(1982), p. 255; FUGARDO (1999), pp. 23 y 29.

${ }_{78}^{78}$ FUGARDO (2007), pp. 172-185.

${ }^{79}$ ANDERSON et al. (2015), p. 99.

${ }^{80}$ LUIS (2008), pp. 47-51; SERRA (2009), pp. 215, 216 y 231.

${ }^{81}$ BONNIER (1929), pp. 23 y 24.
} 
relaciona con el método procesal denominado "reconocimiento" previsto en el art. 346 CPC, que es innecesario para los documentos públicos ${ }^{82}$.

En el Derecho comparado es posible encontrar soluciones en el sentido expuesto. Un ejemplo interesante lo hallamos en el ordenamiento norteamericano donde se consagra una disposición especial para documentos mercantiles que se presumen "auto-autenticables" ("selfauthenticating"), tomándose en cuenta para tales fines las exigencias formales que los rodean y el uso frecuente de ellos en la actividad comercial, lo que puede vincularse al concepto de fe pública comercial. La regla 902.9 FRE atribuye fuerza probatoria a la autenticidad de documentos negociables como los pagarés y otros relacionados, los que -por lo mismo- no requieren prueba extrínseca de genuinidad dada la baja probabilidad de error y el innecesario tiempo y gasto que demandaría dicha actividad probatoria. Los autores señalan que por razones de necesidad y conveniencia en el tráfico comercial el Derecho convierte a tales documentos en "pruebas prima facie" o evidencias con presunción de su propia autenticidad atendidas las "garantías de confiabilidad" que las acompañan y que permiten su circulación ${ }^{83}$.

\section{Valoración probatoria de los documentos públicos mercantiles en la legislación chilena}

\subsection{Prevalencia de criterios jurídicos}

En la legislación nacional existen disposiciones inspiradas en las nociones revisadas anteriormente que permiten sostener que los documentos mercantiles provistos de fe pública se someten a un sistema de valoración en la que predominan criterios jurídicos, aunque con una técnica de intensidad moderada compuesta por reglas de preferencia probatoria. Como se explicará enseguida lo que hace el legislador con este tipo de normas es imponer un criterio de preferencia en favor de las evidencias documentales que los tribunales tienen que aplicar sin necesidad de revisar su cualidad epistémica. Usando las palabras de Lombardo puede decirse que en estos casos tiene lugar un "primer juicio de fiabilidad" de los documentos mercantiles asignado imperativamente por el legislador, que podrá ser desvirtuado por otras evidencias a las que el juez asigne mayor fuerza para demostrar los hechos ${ }^{84}$.

Este tema no ha sido analizado por la doctrina y la jurisprudencia principalmente a causa de la errada idea de que la prueba documental pública en sede comercial estaría sometida de manera exclusiva y excluyente a las normas civiles previstas en los arts. 1699, 1700 y 1706 CC $^{85}$. Esto ha llevado a vincular casi automáticamente la fe pública mercantil con la fe pública notarial pasando por alto dos asuntos relevantes: primero, las aludidas normas legales han sido concebidas para actos y contratos civiles, no para la contratación mercantil; segundo, en el Derecho comercial chileno existen diversas hipótesis reguladas por normas legales expresas donde concurre la fe pública mercantil en su doble vertiente subjetiva y objetiva y-además-con los ya descritos caracteres de flexibilidad y dinamismo que requieren las operaciones de mercado. Quien hizo excepción a este error hermenéutico y propuso una noción amplia de fe pública comercial fue Fueyo, pero su teoría no ha recibido mayor reconocimiento ${ }^{86}$. Algunos fallos han aludido a la fe pública mercantil como un bien jurídico protegido por el legislador a propósito del uso de los títulos valores ${ }^{87}$, aunque se trata de una temática sobre la cual no se ha profundizado lo suficiente.

La errónea interpretación y aplicación de los arts. 1699, 1799 y 1706 CC a la contratación comercial ha provocado como lógica consecuencia que una serie de documentos típicamente mercantiles hayan recibido la incorrecta calificación de pruebas documentales privadas, con la

\footnotetext{
${ }^{82}$ Con referencias doctrinales y jurisprudenciales: SANTA CRUZ (1942), pp. 5 y 6; ANABALÓN (1954), pp. 311 y 316; PALOMO (2014), pp. 310-312; MENESES (2017), pp. 123-128.

83 WEINSSENBERGER Y DUANE (2007), p. 690; GRAHAM (2018), pp. 668, 681 y 682.

${ }^{84}$ LOMBARDO (1992), p. 617.

${ }^{85}$ Denotando una remisión a las categorías documentales del Código civil: CONCHA (1940), pp. 18-24; SHARPE (1944), pp. 18-22.

${ }^{86}$ FUEYO (1982), pp. 157-161 y 191-194; FUEYO (1990), pp. 252-254.

${ }^{87}$ Corte de Apelaciones de Valparaíso, Rol № 519-2012, 31 de mayo de 2012, considerando 50.
} 
consiguiente minusvaloración de su fuerza como evidencias judiciales. Un ejemplo paradigmático son los libros de contabilidad de los empresarios que para la doctrina nacional serían meros documentos privados ${ }^{88}$. Recuérdese que esta clase documental requiere ser reconocida para demostrar su autenticidad y recién ahí alcanzar fuerza probatoria (art. 346 CPC, art. 1702 (C), a diferencia de los documentos públicos tienen la aptitud legal para establecer por sí mismos su genuinidad. Otro punto fundamental es el de la impugnación de estas evidencias, que en el caso de los documentos privados debe ser probada por la parte que los presenta mientras que tratándose de los documentos públicos tiene que hacerlo la parte que formula la objeción, lo que deja a la vista la mejor posición en la que se hallan estos últimos ${ }^{89}$.

No es el lugar para desarrollar este complejo tema que exige precisiones históricas y teóricas que exceden los límites del presente análisis. Con todo, con el objeto de tener una visión de conjunto es posible citar algunos preceptos que en sus fuentes fueron concebidos como expresiones de documentos provistos de fe pública mercantil y que en la actualidad mantienen dicho status aunque, como se dijo, sin mayor estudio dogmático. El Derecho comercial ha tenido y sigue teniendo una concepción probatoria acerca de las evidencias documentales que difiere de la vigente en la legislación civil, la que se manifiesta en preceptos inspirados en la noción especial de fe pública que ha sido expuesta en los epígrafes anteriores ${ }^{90}$. Así ocurre en los arts. 35,38 y 39 CCom con respecto a los libros de contabilidad mercantil cuya eficacia probatoria aparece expuesta mediante la fórmula "hacen fe"; en los arts. 61 CCom y 33 inc. 4 으 Ley N¹8.045, de 1981, relativos a las minutas que expiden los corredores de comercio e intermediarios de valores, cuya fuerza se sintetiza en la frase "hacen prueba"; y en el art. 60 CCom a propósito de los registros de los corredores de comercio que tienen reconocido un valor especial a través de la expresión "se estará". Es perfectamente posible incluir otras categorías documentales de uso frecuente en las actividades del mercado bursátil, financiero y del seguro a las que corresponde aplicar análogos criterios con el propósito de mantener una debida coherencia del orden legal. La base del sistema probatorio de estas evidencias es la fe pública mercantil cuya presencia impone criterios jurídicos de valoración en todos los casos.

\subsection{Reglas de preferencia probatoria}

Las fórmulas usadas por el legislador ("hacen fe", "hacen prueba", "se estará") tienen un significado probatorio que debe recibir debida aplicación en los procesos judiciales, dada la incuestionable vinculación que tiene con la fe pública mercantil. No son conceptos vacíos ni neutros. Son giros del lenguaje por medio de los cuales el legislador atribuye valor probatorio a elementos documentales acompañados de fe pública, cuyo uso habitual en las relaciones de comercio necesitan de la estabilidad y funcionalidad que brinda esta institución. La doctrina española lo ha tenido claro por décadas ${ }^{91}$.

Ahora bien, en el Derecho chileno resulta más consistente entender estas normas no como presunciones iuris tantum sino como reglas de preferencia por medio de las cuales la ley obliga al juez a reconocer suficiencia a estas evidencias documentales con prescindencia de criterios epistémicos, sin perjuicio de la posibilidad que el mérito de ellas sea desvirtuado por las demás probanzas allegadas al proceso. La diferencia radica en la gradación del estándar para lograr derrotar la solución normativa, que -según se indicó antes- es más exigente para las normas de presunciones legales. Como ejemplo puede citarse la legislación alemana donde los $\S \S 415$ y 437 ZPO contemplan reglas de presunciones iuris tantum respecto a la "autenticidad"

\footnotetext{
88 Expresamente: PUGA (2005), p. 33; JEQUIER (2013), pp. 81 y 214; SANDOVAL (2015), p. 151.

89 ANABALÓN (1954), pp. 300-303, 311 y 316; PALOMO (2014), pp. 310-312; MENESES (2017), pp. 123-128, 571 y 572.

90 Sobre la base de los estudios históricos de Brahm puede afirmarse que la concepción probatoria de Ocampo tuvo dentro de sus inspiraciones la doctrina del comercialista español González Huebra, quien estimaba que los documentos mercantiles consistentes en libros de contabilidad y "escrituras oficiales" (o pólizas certificadas por corredores de comercio colegiados) poseían una especie de fe pública que permitía calificarlos como una modalidad de documentos públicos. Véanse respectivamente: BRAHM (2000), pp. 64-69, 101-108, 187, 258 y 448; GONZÁLEZ (1853), pp. 50 y 94.

91 URÍA (1970), p. 135; PRÍES (2016), p. 68.
} 
de los documentos públicos nacionales ( $§ 437$ ) y a la "completud" de la relación sustantiva almacenada en los documentos públicos declarativos (\$ 415), que son derrotables a través de evidencia "directa" aportada a la causa (estándar probatorio alto) ${ }^{92}$. Las reglas de preferencia probatoria pueden entenderse como disposiciones legales que hacen competir a las evidencias documentales en mejor posición frente a otros medios, al tener reconocida por la ley su autenticidad y veracidad. Gozan de antemano de suficiencia probatoria a diferencia de otros elementos que deben ser sometidos a un análisis epistémico para definir su aptitud para demostrar hechos.

En cierto sentido la jurisprudencia ha considerado este estatuto legal especial al referirse a la fuerza probatoria de la contabilidad comercial. Se ha señalado que el art. 38 CCom (regla según la cual los libros de contabilidad mercantil "hacen fe contra el comerciante que los lleva, y no se le admitirá prueba que tienda a destruir lo que resultare de sus asientos") constituye una limitación probatoria para la parte pero no un impedimento para la valoración comparativa de las evidencias que compete a los jueces de la instancia ${ }^{93}$. Esto quiere decir que la norma resulta imperativa para la parte $y$, por ende, los comerciantes deben someterse al mérito de sus libros contables sin que resulte admisible que intenten desvincularse de su fuerza probatoria, lo que no obsta a que los jueces arriben a una conclusión diferente sobre la base de la información proveniente del resto de las evidencias acompañadas a la causa.

Una regulación que se refiere de modo expreso a esta técnica legal es el art 132 inc. 14응 CTrib sobre la fuerza probatoria de la contabilidad fidedigna en los procesos tributarios. Con la fórmula "deberá ponderar preferentemente", la norma asigna un valor preponderante a las anotaciones contables confeccionadas con sujeción a las exigencias legales y reglamentarias. La Corte Suprema califica a esta regla como un "deber de ponderación preferente", que si bien no importa excluir la valoración de otros antecedentes allegados a la causa sí obliga a los jueces a "darle prioridad en tal labor de apreciación a aquélla sobre éstos, frente a una eventual oposición o discordancia de los hechos y asientos de que dan cuenta" ${ }^{94}$.

\subsection{Técnicas de valoración probatoria de las escrituras públicas mercantiles (arts. 129 (Com y 1700 CC)}

El art. 129 CCom es otra manifestación de la concepción probatoria que tiene la fe pública mercantil en el Derecho chileno. Esta norma indica que "los juzgados de comercio podrán, atendidas las circunstancias de la causa, admitir prueba testimonial aun cuando altere o adicione el contenido de las escrituras públicas". Con esta redacción el legislador ha establecido una técnica probatoria distinta de la contenida en el art. 1700 CC, menos intensa y más acorde a las necesidades de flexibilidad y dinamismo de las operaciones mercantiles. La interpretación armónica de los arts. 129 CCom y 1700 CC permite afirmar que las escrituras públicas que contienen negocios mercantiles se someten, por un lado, a una técnica de valoración con contraprueba limitada en cuanto a su autenticidad y, por otro, a una con contraprueba amplia en lo atinente a la veracidad de su contenido; la primera se ciñe a los parámetros de la fe pública notarial pura y simple y la segunda a los criterios propios de la fe pública mercantil.

En efecto, en lo relativo a la autenticidad de estos documentos públicos corresponde aplicar en toda su extensión la primera parte del art. 1700 inc. 1으: "el instrumento público hace plena fe en cuanto al hecho de haberse otorgado y su fecha, pero no en cuanto a la verdad de las declaraciones que en él hayan hecho los interesados". Ello significa que estas evidencias

\footnotetext{
${ }^{92}$ Sobre el punto: DI FAZZIO (2018), pp. 334-339 y 346-350, con discusión bibliográfica.

${ }_{93}$ Corte Suprema, Rol № 3775-2003, de 21 de septiembre de 2004, considerando 8‥ En igual sentido: Corte Suprema, Rol № 16612004, de 7 de noviembre de 2006, considerando 4; ; Corte de Apelaciones de Valparaíso, Rol № 807-2011, de 5 de septiembre de 2011, considerando 3 ‥

${ }_{94}$ Corte Suprema, Rol № 10.220-2017, de 18 de octubre de 2018, considerandos 5o y 7o. Refiriéndose al "deber de ponderación preferente": Corte Suprema, Rol № 7312-2015, de 1 de agosto de 2016, considerando 60; Corte Suprema, Rol № 12.874-2015, de 7 de diciembre de 2016, considerandos 14ㅇ y 19; Corte Suprema, Rol № 7371-2016, de 16 de enero de 2017, considerando 70; Corte Suprema, Rol № 24.418-2016, de 14 de septiembre de 2017, considerandos 6 y 9o; Corte Suprema, Rol № 58.900-2016, de 12 de diciembre de 2017, considerando 5․
} 
tienen reconocida una suficiencia probatoria en lo tocante a su genuinidad que solamente puede desvirtuarse en la medida que la parte interesada formule un procedimiento de impugnación y demuestre el o los motivos de la objeción documental. Es el sentido y alcance que corresponde dar a la expresión "hace plena fe" empleada en la norma tal como lo ha entendido la doctrina reciente $^{95}$, y como lo ha establecido la jurisprudencia del último tiempo en los siguientes sentidos: trazando una diferencia entre cuestionar el valor probatorio asignado por los jueces y formular un procedimiento de impugnación documental que permita desvirtuar la fuerza de estas evidencias ${ }^{96}$, haciendo primar el carácter de plena prueba atendida la ausencia de objeción por la parte afectada ${ }^{97}$, desconociendo la idoneidad de una mera alegación de falsedad ideológica de un instrumento público para restarle el valor de plena prueba asignado por la ley ${ }^{98}$ $y$, reconociendo que la plena fe indicada por el art. 1700 CC constituye un mérito probatorio bastante para dispensar de toda otra prueba a quien invoca este medio ${ }^{99}$.

En cambio, lo tocante a la veracidad o sinceridad del negocio documentado se somete a la regla especial del art. 129 CCom que no exige un procedimiento de impugnación sino la presencia de prueba testimonial rendida en la causa. Así, para las escrituras públicas mercantiles no resulta aplicable la segunda parte del art. 1700 inc. 1ㅇ CC que impone la misma técnica con contraprueba limitada para la veracidad del contenido: "en esta parte no hace plena fe sino contra los declarantes". Aquí procede una técnica con contraprueba amplia que cabe identificar con las reglas de presunciones legales simples, pues si bien el legislador admite contradecir las declaraciones contenidas en las escrituras públicas mercantiles mediante evidencia testifical y sin necesidad de objeción documental, establece un estándar alto: "atendidas las circunstancias de la causa". En otros términos, estos documentos públicos constituyen evidencias con mérito suficiente para comprobar la veracidad o sinceridad del contenido negocial consignado en ellos, a menos que en casos calificados ("atendidas las circunstancias de la causa") los dichos de los testigos que han comparecido al proceso contradigan de manera clara y precisa lo expuesto en las escrituras públicas, alterando o adicionando su contenido. La doctrina y la jurisprudencia coinciden en exigir que la testifical reúna condiciones de claridad y precisión suficientes para desvirtuar o modificar el contenido documental, señalando en tal sentido que los jueces tienen una facultad discrecional para decidir en el caso concreto si conceden o no mayor fuerza a los dichos de los testigos debiendo examinar críticamente esta evidencia ${ }^{100}$, y sobre todo desconociendo la aptitud de los testimonios de oídas ${ }^{101}$.

Esta combinación de técnicas tiene cabal sentido si se toma en cuenta el significado de la fe pública en la documentación de negocios comerciales, pues si bien ambos rubros autenticidad y veracidad- se hallan cubiertos por la fe pública notarial, el legislador le asigna una eficacia diferente en cada ámbito. Considerando las solemnidades que rodean la extensión y conservación de escrituras públicas la ley impone una técnica de apreciación probatoria más estricta en cuanto a la autenticidad (art. 1700 inc. 10 CC). Pero el antiformalismo propio del Derecho comercial, la fluidez y rapidez de las relaciones de mercado y la necesaria funcionalidad que deben tener los documentos en el intercambio de bienes y servicios con fines de lucro han servido de fundamento para modificar la estrategia regulatoria a propósito de la veracidad de las declaraciones consignadas en las escrituras públicas (art. 129 CCom).

Por ello, carecen de sentido las durísimas críticas formuladas por los autores nacionales en contra de la regla probatoria del art. $129 \mathrm{CCom}$, para quienes se trata de una norma que habría que derogar para así restaurar en plenitud el estatuto civil ${ }^{102}$. No hay fundamento para

\footnotetext{
95 Expresamente en doctrina: MENESES (2017), pp. 542-544; CORRAL (2018), p. 785.

${ }^{96}$ Corte Suprema, Rol № 21.762-1993, de 26 de junio de 1997, considerando 9o.

${ }^{97}$ Corte Suprema, Rol № 6033-2006, de 24 de diciembre de 2007, considerando 4ㅇ․

${ }^{98}$ Corte Suprema, Rol № 6297-2015, de 8 de septiembre de 2015, considerandos 8ㅇ y 9ㅇ.

${ }_{99}$ Corte Suprema, Rol № 18.313-2016, de 18 de octubre de 2016, considerandos 14ㅇy y 15ㅇ; Corte Suprema, Rol № 5064-2017, de 25 de junio de 2018, considerando 60.

100 PALMA (1935), p. 187; CONCHA (1938), p. 22; SHARPE (1944), p. 22; MENDOZA (1952), pp. 266 y 267.

${ }^{101}$ Corte Suprema, Rol № 1747-2017, de 19 de abril de 2018, considerando 10; Corte Suprema, Rol № 101.740-2016, de 9 de enero de 2019, considerandos 30 y 31ㅇ.

102 IBÁNEZ (1890), pp. 66 y 67; PALMA (1935), p. 187; CONCHA (1938), p. 22; SHARPE (1944), p. 21; MENDOZA (1952), pp. 266 y 267.
} 
propugnar dicho cambio. Por el contrario, aquí militan fuertes razones para mantener esta técnica de valoración que resulta plenamente concordante con la noción de fe pública mercantil expuesta en los epígrafes anteriores. La única norma que mantiene pleno vigor para los negocios mercantiles es la del art. 1701 inc. 10 CC relativa a los instrumentos públicos exigidos como solemnidad, materia donde no sólo concurren consideraciones sustantivas y probatorias asociadas el establecimiento de los hechos, sino una particular manera de regular la generación válida de actos jurídicos ${ }^{103}$.

\section{Conclusiones}

Sintetizando el análisis contenido en este trabajo pueden consignarse las siguientes conclusiones:

a) La valoración de la prueba es una actividad de juzgamiento fáctico compuesta por conocimiento y decisión, en la que se combinan criterios epistémicos y jurídicos junto con factores argumentativos y psicológicos.

b) Cada ordenamiento determina la prevalencia de tales criterios y factores sobre la base de una multiplicidad de consideraciones epistemológicas, prácticas y estratégicas. Por ello, en lugar de plantear modelos teóricos dicotómicos (prueba libre, prueba legal), lo adecuado es presentar una perspectiva integrada de valoración probatoria en la que predominarán unos $u$ otros parámetros según las opciones adoptadas en cada sistema.

c) La prevalencia de criterios jurídicos de valoración probatoria se justifica en todas aquellas situaciones donde los cánones epistémicos resultan insuficientes para la decisión judicial sobre los hechos, en especial cuando la legislación sustantiva ha adoptado medidas tendientes a alcanzar finalidades relevantes que no resultan plenamente conciliables con la búsqueda de la verdad fáctica. Debe existir una comunión entre las soluciones previstas por el Derecho sustantivo y las decisiones jurisdiccionales sobre hechos.

d) La valoración probatoria de los documentos públicos mercantiles reconoce una prevalencia de criterios jurídicos en virtud de la fe pública que detentan. La fe pública mercantil es una creación del Derecho comercial compuesta por un conjunto normativo que disciplina la actividad documentadora de negocios y por el valor jurídico-probatorio que la ley confiere a los elementos que son el resultado de dicha actividad documentadora. Es una institución jurídica concebida para permitir el desarrollo seguro y eficiente del tráfico mercantil a través de medidas dinámicas y flexibles, que en el plano de las pruebas judiciales consisten en técnicas legales de valoración con contraprueba amplia.

e) La prevalencia de criterios jurídicos de valoración de esta evidencia documental es indispensable para mantener una interacción entre las medidas de seguridad y eficiencia previstas por la ley sustantiva y el establecimiento judicial de los hechos. Por consiguiente, en este caso los parámetros epistémicos quedan subordinados a las soluciones normativas de suficiencia probatoria, sin perjuicio de la prueba en contrario. En otras palabras, tratándose de los documentos provistos de fe pública mercantil las normas legales sobre suficiencia probatoria prevalecen sobre las reglas de la sana crítica, las que sólo se aplicarán al momento de apreciar la contraprueba.

f) En el Derecho chileno la técnica legal de valoración aplicable a los documentos provistos de fe pública mercantil consiste en reglas de preferencia probatoria, que imponen a los tribunales el deber de reconocer suficiencia a estas evidencias a menos que las demás probanzas de la causa logren desvirtuar su autenticidad y veracidad. Estas reglas tienen una fuerza normativa inferior a las disposiciones sobre presunciones legales relativas, al no imponer un estándar elevado para derrotar las soluciones previstas por el legislador.

g) La técnica con contraprueba limitada del art. 1700 CC no se aplica a los documentos públicos mercantiles, con la sola excepción de las escrituras públicas respecto a las cuales -en

${ }^{103}$ Sobre la vigencia estricta del art. 1701 CC para los actos y contratos mercantiles: PALMA (1935), p. 187; CONCHA (1938), p. 22; SHARPE (1944), p. 22; BAEZA (2008), p. 1566. 
cualquier caso- solamente rige la primera parte (autenticidad), pues lo referido a la veracidad de su contenido se somete a una norma especial contenida en el art. 129 CCom. Esta regla contempla una técnica de valoración con contraprueba amplia calificable como una presunción legal iuris tantum, que bajo la fórmula "atendidas las circunstancias de la causa" impone un estándar alto para derrotar la solución normativa mediante declaraciones de testigos.

\section{BIBLIOGRAFÍA CITADA}

ANABAlón SANDERSON, CARlos (1954): El juicio ordinario de mayor cuantía (Santiago, Editorial Jurídica de Chile).

ANderson, Terence; SCHUM, DAVID y TWINING, WILLIAM (2015): Análisis de la prueba (Traducc. Flavia Carbonell y Claudio Agüero, Madrid, Marcial Pons).

ANSANELLI, VINCENZo (2017): "Pruebas e instrumentos cognoscitivos del juez", en: Dondi, Angelo; Ansanelli, Vincenzo y Comoglio, Paolo, Procesos civiles en evolución. Una perspectiva comparada (Madrid, Marcial Pons), pp. 195-246.

Baeza Ovalle, Gonzalo (2008): Tratado de Derecho comercial, 4a edición (Santiago, Thomson Reuters), tomo III.

Bayón Mohino, Juan Carlos (2008): “Epistemología, moral y prueba de los hechos: hacia un enfoque no benthamiano", en: Comanducci, Paolo y Guastini Riccardo (Dirs.), Analisi e Diritto (Madrid, Marcial Pons), pp. 15-34.

BENFELD ESCOBAR, JOHANN (2018a): "Sobre el carácter normativo y tendencialmente vinculante de las reglas de la sana crítica en la ponderación de la prueba judicial", en: Revista de Derecho, Pontificia Universidad Católica de Valparaíso (Vol. 50), pp. 159-185.

BENFELD ESCOBAR, JOHANN (2018b): “Sobre la formalización de las reglas de la sana crítica. Puntos de contacto y diferencia entre el sistema de ponderación libre de J. Bentham y el sistema de prueba tasada bajo medieval de las Siete Partidas y sus textos herederos", en: Benfeld, Johann y Larroucau, Jorge (Eds.), La sana crítica bajo sospecha (Valparaíso, Ediciones Universitarias de Valparaíso), pp. 93-113.

BENTHAM, JeREMÍAs (1971): Tratado de las pruebas judiciales. Obra compilada de los manuscritos del autor por E. Dumont (Traducc. Manuel Ossorio y Florit, Buenos Aires, Ejea), volumen I.

BONet NAVARRo, JosÉ (2009): La prueba en el proceso civil. Cuestiones fundamentales (Madrid, Difusión Jurídica).

BONNIER, EDUARDO (1929): Tratado teórico y práctico de las pruebas en Derecho civil y en Derecho penal, 5a edición (Traducc. José Vicente y Caravantes, Madrid, Reus), tomo II.

Brahm García, EnRIQUe (2000): José Gabriel Ocampo y la codificación comercial chilena. Los primeros borradores del proyecto de Código de comercio (Santiago, Universidad de los Andes, Colección Jurídica №5), tomo I.

CABAÑAS GARCía, JUAN CARLOS (1992): La valoración de las pruebas y su control en el proceso civil (Madrid, Trivium).

CANestrelli, Serena (2010): Istruzione probatoria e libero convincimento del giudice (Milán, Università degli Studi di Milano - Bicocca).

CAPpelletti, Mauro (2002): El testimonio de la parte en el sistema de la oralidad. Contribución a la teoría de la utilización probatoria del saber de las partes en el proceso civil. Parte primera (Traducc. Tomás A. Banzhaf, Buenos Aires, Platense).

Carbonell Bellolio, Flavia (2017): "Elementos para un modelo de decisión judicial correcta", en: Revista de Estudios de la Justicia (№ 27), pp. 1-35. 
ChIOVEndA, GuISEPPE (1922): Principios de Derecho Procesal Civil, 3a edición (Traducc. José Casais y Santaló, Madrid, Reus), tomo II.

Coloma CoRrea, Rodrigo (2018): "Más allá de reglas mínimas de sana crítica”, en: Benfeld, Johann y Larroucau, Jorge (Eds.), La sana crítica bajo sospecha (Valparaíso, Ediciones Universitarias de Valparaíso), pp. 139-150.

Coloma CoRrea, Rodrigo y Agüero SAN JUAN, Claudio (2014): "Lógica, ciencia y experiencia en la valoración de la prueba", en: Revista Chilena de Derecho, Pontificia Universidad Católica de Chile (Vol. 41, № 2), pp. 673-703.

COMOGLIO, LUIGI PAOLO (2010): Le prove civil, 3a edición (Turín, Utet Giuridica).

CONCHA RIVAS, MAXIMILIANO (1938): De la prueba en el Derecho comercial (Santiago, Imprenta López Hermanos, Memoria de licenciatura).

CONTRERAS RojAS, CRISTIAN (2015): La valoración de la prueba de interrogatorio (Madrid, Marcial Pons).

CoRRAL TALCIANI, HeRnÁn (2018): Curso de Derecho civil. Parte general (Santiago, Thomson Reuters).

Couture, EduARDo (1989): “El concepto de fe pública (Introducción al estudio del Derecho notarial)", en: Couture, Eduardo, Estudios de Derecho procesal civil, 3a edición (Buenos Aires, Depalma), tomo II, pp. 13-125.

DAMAŠKA, MIRJAN (2015): El Derecho probatorio a la deriva (Traducc. Joan Picó, Madrid, Marcial Pons).

DENTI, VITTORIO (1957): La verificazione delle prove documentali (Turín, Unione Tipografico-Editrice Torinese).

DeVIS EChANDÍA, HeRnANDo (2002): Teoría general de la prueba judicial, 5a edición (Bogotá, Temis), tomol.

DI FAzzıO, GIULIA (2018): Contributo allo studio della prova documentale publica (Torino, G. Giappichelli Editore).

EtCheBerRy, Alfredo (1961): "El objeto jurídico de los delitos de falsedad documental", en: Revista de Ciencias Penales, Instituto de Ciencias Penales-Chile, (t. XX, № 1), pp. 33-66.

FERRAJOLI, LUIGI (1998): Derecho y razón. Teoría del garantismo penal, 3a edición (Traducc. Perfecto Andrés Ibáñez y otros, Madrid, Trotta).

FerRer Beltrán, JoRDi (2005): Prueba y verdad en el Derecho, 2a edición (Madrid, Marcial Pons).

FerReR BeltrÁN, JORDI (2007): La valoración racional de la prueba (Madrid, Marcial Pons).

FerReR Beltrán, JoRDI (2013): “La prueba es libertad, pero no tanto: una teoría de la prueba cuasibenthamiana", en: Vásquez, Carmen (Ed.), Estándares de prueba y prueba científica. Ensayos de epistemología jurídica (Madrid, Marcial Pons), pp. 21-39.

FORNIÉS, ASCENSIÓN (1975): “Concepto general de la fe pública mercantil”, en: Contreras, José Luis; Domingo, Vicente; Duque, Faustino; Forniés, Ascensión; Gutiérrez de Cabiedes, Eduardo; Martínez de Aguirre, Manuel; Prieto Castro, Leonardo y, Sánchez Calero, Fernando, La fe pública mercantil. Primer seminario (Pamplona, Ediciones Universidad de Navarra), pp.17-49.

FueYo LANERI, FERNANDo (1982): Teoría general de los registros (Buenos Aires, Astrea).

FueYo LANERI, FERnANDo (1990): Instituciones de Derecho Civil moderno (Santiago, Editorial Jurídica de Chile). 
FUGARDO ESTIVILL, JOSÉ MARÍA (1999): Fe pública mercantil: fuentes, organización y régimen jurídico. Comentario a la reforma del Reglamento del Cuerpo de Corredores de Comercio Colegiados (RD 1251/1997, de 24 de julio) Disposiciones vigentes (Madrid, Marcial Pons).

FUGARDO ESTIVILL, JOSÉ MARÍA (2007): “La reforma de la legislación notarial y la regulación de la póliza intervenida", en: Garrido Melero, Martín (Dir.), El notariado y la reforma de la fe pública (Madrid, Civitas), pp. 133-216.

Furno, CARLo (1954): Teoría de la prueba legal (Traducc. Sergio González Collado, Madrid, Editorial Revista de Derecho Privado).

García AmAdo, JuAn Antonio (2014): “Elementos para el análisis de la prueba y del razonamiento probatorio en Derecho", en: García, Juan Antonio y Bonorino, Pablo (Coords.), Prueba y razonamiento en Derecho: debates sobre abducción (Granada, Comares), pp. 43-81.

GARRIDO MONTT, MARIO (2008): Derecho Penal. Parte especial, 4a edición (Santiago, Editorial Jurídica de Chile), tomo IV.

GASCón ABelLÁn, MARINA (2004): Los hechos en el Derecho. Bases argumentales de la prueba (Madrid, Marcial Pons).

GASCÓN ABELLÁN, MARINA (2005): "Sobre la posibilidad de formular estándares de prueba objetivos", en: Doxa. Cuadernos de Filosofía del Derecho (№ 28), pp. 127-139.

GÓMEZ SEGADE, JOSÉ ANTONIO (1977): “La intervención de agente mediador y la seguridad del tráfico mercantil". En: Bercovitz, Alberto (Coord.), La fe pública mercantil. Tercer seminario (Valencia, Ediciones Saetabis), pp. 25-59.

GonZÁlez Huebra, PABLo (1853): Curso de Derecho mercantil (Madrid, Imprenta C. González), tomo I.

GonzÁlez LAgIeR, DANIEl (2014): "Presunción de inocencia, verdad y objetividad", en: García, Juan Antonio y Bonorino, Pablo (Coords.), Prueba y razonamiento en Derecho: debates sobre abducción (Granada, Comares), pp. 83-112.

GonzÁlez LAgIeR, DANIEL (2018): “Distinciones, estipulaciones y sospechas sobre los criterios de valoración y los estándares de prueba", en: Benfeld, Johann y Larroucau, Jorge (Eds.), La sana crítica bajo sospecha (Valparaíso, Ediciones Universitarias de Valparaíso), pp. 15-32.

Graham, Michael H. (2018): Federal Rules of Evidence. In a nutshell, 10a edición (Saint Paul, West Academic Publishing).

GutiérRez Del Solar y Bragado, Eduardo (1982): La fe pública extranotarial (Madrid, Editorial Revista de Derecho Privado).

HUIDOBRO SALAS, RAMÓN (2010): “Orden público económico y regulación (Notas sobre la regulación de la actividad comercial por vía electrónica)", en: Revista de Derecho Público (vol. 73), pp. 243260.

HUNTER AMPUero, IVÁn (2017): "Reglas de prueba legal y libre valoración de la prueba ¿Cómo conviven en el Proyecto de Código Procesal Civil?", en: Revista lus et Praxis, Universidad de Talca (Año 23, № 1), pp. 247-272.

IACOBONI, ALESSANDRo (2006): Prova legale e libero convincimento del giudice (Milán, Giuffrè).

IBÁÑEZ, MAXIMILIANo (1890): Revisión del Código de comercio (Paris, Imprimerie Paul Dupont, Memoria de licenciatura).

ISLER SOTO, ERIKA (2019): Derecho del consumo. Nociones fundamentales (Valencia, Tirant lo Blanch). 
Jequier Lehuedé, Eduardo (2013): Curso de Derecho Comercial (Santiago, LegalPublishing / Thomson Reuters), tomo I.

JiMÉNEZ CONDE, FERNANDO (1978): La apreciación de la prueba legal y su impugnación (Salamanca, Universidad de Salamanca, Publicaciones del Departamento de Derecho Procesal).

Jiménez Valenzuela, Claudio y Fouillioux Puentes, Pascale (2018): "Consideraciones para un concepto de error procesal (una mirada desde el Análisis Económico del Derecho)", en: Carrasco, Nicolás (Coord.), Análisis Económico del Derecho procesal: nuevas perspectivas (Santiago, Editorial Jurídica de Chile), pp. 119-157.

LARROUCAU TORRES, JORGE (2018): "Las Federal Rules of Evidence norteamericana y la codificación de las leyes reguladoras de la prueba", en: Benfeld, Johann y Larroucau, Jorge (Eds.), La sana crítica bajo sospecha (Valparaíso, Ediciones Universitarias de Valparaíso), pp.115-137.

LOMBARDO, LUIGI (1992): "Riflessioni sull'attualità della prova legale", en: Rivista trimestrale di Diritto e procedura civile (№ 2), pp. 611-630.

LOMBARDO, LUIGI (1999): La prova giudiziale. Contributo alla teoria del giudizio di fatto nel proceso (Milán, Giuffrè).

Maturana BAezA, Javier (2014): Sana crítica. Un sistema de valoración racional de la prueba (Santiago, LegalPublishing / Thomson Reuters).

Mendoza BAHAMONDE, JORGE (1952): De la prueba testifical en materia substantiva civil (Concepción, Escuela tipográfica Salesiana, Memoria de licenciatura).

Meneses PACHeCo, ClaUdio (2017): El documento público como medio de prueba en el proceso civil chileno (Santiago, Thomson Reuters).

Meneses Pacheco, Claudio (2018): "Significado de la fe pública en la prueba por medio de documentos públicos", en: Revista de Derecho. Universidad Católica del Norte (Año 25, № 1), pp. 181-230.

Montero Aroca, JUAN (2012): La prueba en el proceso civil, 7ạ edición (Madrid, Civitas / Thomson Reuters).

MONTERO LóPEZ, RAÚl (2017) Necesidad de establecer un estándar de prueba en el nuevo proceso civil chileno (Santiago, Librotecnia).

Nieva FenOlL, JoRdi (2010): La valoración de la prueba (Madrid, Marcial Pons).

NieVA FenOLL, JORDI (2018): Inteligencia artificial y proceso judicial (Madrid, Marcial Pons).

NúÑez Lagos, Rafael (1986a) “La fe pública”, en: Núñez Lagos, Rafael, Estudios de Derecho Notarial (Madrid, Instituto de España), tomo I, pp. 329-362.

NúÑez Lagos, Rafael (1986b) "Perfiles de la fe pública”, en: Núñez Lagos, Rafael, Estudios de Derecho Notarial (Madrid, Instituto de España), tomo I, pp. 455-480.

Palma Rogers, Gabriel (1935): Derecho comercial. Apuntes de clases (Santiago, Talleres Gráficos Artuffos).

Palomo Vélez, Diego (2014): "La fase de prueba”, en: Bordalí, Andrés; Cortez, Gonzalo y Palomo, Diego, Proceso civil. El juicio ordinario de mayor cuantía, procedimiento sumario y tutela cautelar (Santiago, LegalPublishing / Thomson Reuters), pp. 205-397.

PELOSI, CARLOS (2006): El documento notarial, 4a reimpresión (Buenos Aires, Astrea).

Peñallillo Arévalo, Daniel (1993): La prueba en materia sustantiva civil. Parte general (Santiago, Editorial Jurídica de Chile). 
Peñailillo ARÉVAlo, DANiel (2009): Obligaciones. Teoría general y clasificaciones. La resolución por incumplimiento (Santiago, Editorial Jurídica de Chile).

Pérez Ragone, Álvaro (2018): “El impacto del diálogo entre Derecho sustantivo y Derecho procesal", en: Revista Derecho del Estado, Universidad Externado de Colombia (№ 41), pp. 255283.

PRíEs PicARdo, Adolfo (2016): Sobre la fe pública mercantil (Pamplona, Civitas / Thomson Reuters). PUGA VIAL, JUAN Esteban (2005): El acto de comercio. Crítica a la teoría tradicional (Santiago, Editorial Jurídica de Chile).

Rodríguez AdRAdOS, ANTONIO (1996): “Fe pública”, en: Rodríguez Adaros, Antonio, Escritos Jurídicos, Madrid, Colegios Notariales de España (Vol. III), pp. 175-186.

Rojas Martínez Del Mármol, María del Pilar (2003): El ejercicio privado de la fe pública notarial. Examen jurídico-administrativo (Madrid, Marcial Pons).

SANDOVAL LóPEZ, RICARDO (2015): Derecho comercial (Santiago, Editorial Jurídica de Chile), tomo I.

Santa Cruz Serrano, Víctor (1942): "El instrumento público", en: Revista de Derecho y Jurisprudencia, (t. 39), pp. 5-60

Sentís Melendo, SANTIAgo (1979): La prueba. Los grandes temas del Derecho probatorio (Buenos Aires, Ejea).

Serra Domínguez, Manuel (2009): “Prueba documental”, en: Serra Domínguez, Manuel, Estudios de Derecho Procesal (Lima, Communitas), pp. 201-248.

Sharpe CARTE, Mario (1944): De la prueba en el Derecho mercantil (Santiago, Memoria de Licenciatura, Talleres Gráficos Simiente).

StEIN, AleX (2005): Foundations of Evidence Law (New York, Oxford University Press).

STEIN, Alex (2013): “Contra la 'prueba libre'”, en: Revista de Derecho, Universidad Austral (Vol. 26, № 2), pp. 245-261.

SUMMER, ROBERT S. (1999): "Formal legal truth and substantive truth in judicial fact-finding - Their justified divergence in some particular cases", en: Law and Philosophy (Vol. 18, № 5), pp. 497-511.

TARUfFO, MiChele (2002): La prueba de los hechos (Traducc. Jordi Ferrer, Madrid, Trotta).

TARUfFO, MiCHELE (2010): Simplemente la verdad (Traducc. Daniela Accatino, Madrid, Marcial Pons).

Uría González, Rodrigo (1970): “Consideraciones sobre la fe pública mercantil”, en: AA.VV., Coloquio de Derecho Bursátil (Bilbao, Universidad de Bilbao, Facultad de Ciencias Políticas, Económicas y Comerciales), pp. 121-152.

WeISSENBERGER, GLEN Y DUANE, JAMES J. (2007): Federal Rules of Evidence: Rules, Legislative History, Commentary and Authority (New York, LexisNexis).

WRÓBLEWSKI, JERZY (2013): Sentido y hecho en el Derecho (Traducc. Juan Igartua y Francisco Javier Ezquiaga, Lima, Grijley).

\section{JURISPRUDENCIA CITADA}

Contra Contreras Rolack, Patricio Hernán (1996): Corte de Apelaciones de San Miguel 3 de mayo de 1996 (falsificación de documento), Rol № 863-1996 en: Revista de Derecho y Jurisprudencia, t. 93, sec. 4a , pp. 152-155.

MEZA CON CRUZ Y OTRA (1997): Corte Suprema 26 de junio de 1997 (juicio ordinario de nulidad de contrato), Rol № 21.762-1993, en: Westlaw CL/JUR/1594/1997. 
CASTILLO CON LEDEZMA (2004): Corte Suprema 21 de septiembre de 2004 (juicio ordinario de cobro de pesos), Rol № 3775-2003, en: Westlaw CL/JUR/5069/2004.

BANCO BRASIL S.A CON CORNEJO CHACOFF (2006): Corte Suprema 7 noviembre 2006 (juicio ordinario por nulidad de contrato), Rol № 1661-2004, en: Westlaw CL/JUR/3603/2006.

BARRIENTOS CON URIBE (2007): Corte Suprema 24 de diciembre de 2007 (juicio ordinario de resolución de contrato), Rol № 6033-2006, en: Westlaw CL/JUR/6443/2007.

Banco de Chile con ORMeÑo (2010): Corte Suprema 1 de septiembre de 2010 (juicio ejecutivo obligación de dar), Rol № 5842-2010, en: Westlaw CL/JUR/6530/2010.

SOCIEDAd COMERCIAL SANTA INÉS LIMITADA CON SERVICIO DE IMPUESTOS INTERNOS (2011): Corte Suprema 5 de septiembre de 2011 (incidente de nulidad), Rol № 807-2011, en: Westlaw CL/JUR/7434/2011.

Aguilar con Aguilar (2012): Corte Suprema 4 de abril de 2012 (juicio ordinario de nulidad de testamentos), Rol № 6084-2011, en: Westlaw CL/JUR/3727/2012.

SOCIEDAd PESQUeRA ENTRE ISLAS LTDA. CON GATICA (2012): Corte Suprema 5 abril 2012 (juicio ordinario de reivindicación), Rol № 11.745-2011, en: Westlaw CL/JUR/773/2012.

Ministerio Público Contra AntonucCi (2012): Corte de Apelaciones de Valparaíso 31 de mayo de 2012, Rol № 519-2012, en: VLex-378438574.

ARANDA CON ESSATS.A. (2012): Corte Suprema 1 de junio de 2012 (juicio ordinario de indemnización de perjuicios), Rol № 9047-2009, en: Westlaw CL/JUR/3957/2012.

GARCíA CON FISCO DE CHILE (2012): Corte Suprema 21 de junio de 2012 (juicio de reclamación de monto de indemnización por expropiación), Rol № 3454-2012, en: Westlaw CL/JUR/4329/2012.

Rojas CON SERVIU REgIÓN Del MAULE (2012): Corte Suprema 11 de septiembre de 2012 (juicio de reclamación de monto de indemnización por expropiación), Rol № 7990-2009, en: Westlaw CL/JUR/2038/2012.

Sociedad Chilena de Derecho de Autor con Sociedad Agrícola y Ganadera San LUis LtDa. (2015): Corte Suprema 15 de enero de 2015 (juicio sumario de indemnización de perjuicios), Rol № 4560-2014, en: Westlaw CL/JUR/195/2015.

Banco del Estado de CHILE CON CoRtés (2015): Corte Suprema 8 de septiembre de 2015 (juicio ordinario de cobro de pesos), Rol № 6297-2015, en: Westlaw CL/JUR/5210/2015.

Servicio de Procesamiento de datos en Línea S.A. con Servicio de Impuestos Internos (2016): Corte Suprema 1 de agosto de 2016 (reclamación de liquidaciones tributarias), Rol № 7312-2015, en: Westlaw CL/JUR/5416/2016.

SOLíS DE OVANDO CON Solís (2016): Corte Suprema 18 de octubre de 2016 (juicio ordinario declarativo sobre revocación de mandato), Rol № 18.313-2016, en: Westlaw CL/JUR/7137/2016.

Feria Ganaderos Osorno S.A con Servicio de Impuestos Internos (2016): Corte Suprema 7 de diciembre de 2016 (reclamación de liquidaciones tributarias), Rol № 12.874-2015, en: Westlaw CL/JUR/8196/2016.

INVERSIONES NUEVA LOS LINGUE LTDA. CON SERVICIO DE IMPUESTOS INTERNOS (2017): Corte Suprema 16 de enero de 2017 (reclamación de liquidaciones tributarias), Rol № 7371-2016, en: Westlaw CL/JUR/361/2017.

DORIC Y OTROS CON TRUIILLO Y OTROS (2017): Corte Suprema 17 de agosto de 2017 (juicio ordinario de reivindicación), Rol № 92.849-2016, en: Westlaw CL/JUR/5429/2017.

LÓPEZ FILIPICH CON SERVICIO DE IMPUESTOS INTERNOS (2017): Corte Suprema 14 de septiembre de 2017 (reclamación de liquidaciones tributarias), Rol № 24.418-2016, en: Westlaw CL/JUR/6035/2017. 
SOdimAC S.A CON SERVICIO DE IMPUESTOS INTERNOS (2017): Corte Suprema 12 de diciembre de 2017 (reclamación de liquidaciones tributarias), Rol № 58.900-2016, en: Westlaw CL/JUR/7871/2017.

TALA CON BANCO DE CRÉDITO E INVERSIONES (2018): Corte Suprema 19 de abril de 2018 (juicio ordinario de indemnización de perjuicios), Rol № 1747-2017, en: Westlaw CL/JUR/1800/2018.

QUEIROLO CON ARENAS Y OTRO (2018): Corte Suprema 25 de junio de 2018 (juicio sumario de precario), Rol № 5064-2017, en: Westlaw CL/JUR/3123/2018.

Copefrut Agrícola S.A CON SERVICIO de IMPUestos INTERnos (2018): Corte Suprema 18 de octubre de 2018 (reclamación de liquidaciones tributarias), Rol № 10.220-2017, en: Westlaw CL/JUR/5890/2018.

YARUR CON YARUR (2019): Corte Suprema 9 de enero de 2019 (juicio sumario de cobro de honorarios), Rol № 101.740-2016, en: Westlaw CL/JUR/138/2019.

\section{NORMAS JURÍDICAS CITADAS}

CódIGo CIVIL. DFL № 1, fija texto refundido, coordinado y sistematizado del Código civil. Diario oficial, 30 de mayo de 2000.

CódIGO DE COMERCIO. Diario oficial, 23 de noviembre de 1865. 21a edición oficial aprobada por DS $N^{\circ} 1368$, de 25 de junio de 2014.

CÓDIGO DE PROCEDIMIENTO CIVIL. Diario oficial, 30 de agosto de 1902. 25a edición oficial aprobada por DS N 1592, de 1 de agosto de 2019.

Código deL TRABAJO. Diario oficial, 16 de enero de 2003. 27ạ edición oficial aprobada por DS N¹30, de 17 de enero de 2019.

CódIGO ORGÁNICO DE TRIBUNALES. Diario oficial, 9 de julio de 1943. 36a edición oficial aprobada por DS N 1976, de 14 de octubre de 2019.

CódIGO TRIBUTARIO. Diario oficial, 31 de diciembre de 1974. 34a edición oficial aprobada por DS Nº 150, de 28 de enero de 2019.

CONSTITUCIÓN PoLíTICA DE LA REPÚBLICA. DS N¹00, fija texto refundido, coordinado y sistematizado de la Constitución Política de la República, Diario oficial, 22 de septiembre de 2005.

DECRETO LEY № 3.475, que modifica la Ley de timbres y estampillas. Diario oficial, 4 de septiembre de 1980.

DeCREto supremo № 181, Ministerio de Economía, Fomento y Reconstrucción, que aprueba el Reglamento de la Ley №19.799 sobre documentos electrónicos, firma electrónica y la certificación de dicha firma. Diario oficial, 17 de agosto de 2002.

FEDERAL RULES OF EVIDENCE de Estados Unidos de Norteamérica, de 2 de enero de 1975. Edición 20182019 preparada por el profesor Daniel J. Capra, Saint Paul, Minnesota, West Academic Publishing, 2018.

LEY № 18.045, sobre mercado de valores. Diario oficial, 22 de octubre de 1981.

LEY № 18.287, sobre procedimiento ante los Juzgados de Policía Local. Diario oficial, 7 de febrero de 1984.

LEY № 19.799 sobre documentos electrónicos, firma electrónica y servicios de certificación de dicha firma. Diario oficial, 12 de abril de 2002.

LEY № 20.600, que crea los tribunales ambientales. Diario oficial, 28 de junio de 2012. 
Proyecto de ley de Código procesal civil para la República de Chile año 2012. Boletín № 8197-07, facsímil distribuido por el Ministerio de Justicia, Santiago, 2012.

ZIVILPROZESSORDNUNG DE ALEMANIA, de 30 de enero de 1877, en la nueva versión publicada el 5 de diciembre de 2005, con enmiendas introducidas los años 2006 y 2007. 61ạ edición revisada, según estado del día 1 de junio de 2019, Múnich, Editorial Deutscher Taschenbuch Verlag, 2019. 